\title{
Article
}

Subscriber access provided by KIT Library

\section{Quantum Chemical Investigation of the Selenite Incorporation into the Calcite (10-14) Surface}

Robert Polly, Frank Heberling, Bernd Schimmelpfennig, and Horst Geckeis

J. Phys. Chem. C, Just Accepted Manuscript • DOI: 10.1021/acs.jpcc.7b03499 • Publication Date (Web): 28 Aug 2017

Downloaded from http://pubs.acs.org on September 4, 2017

\section{Just Accepted}

"Just Accepted" manuscripts have been peer-reviewed and accepted for publication. They are posted online prior to technical editing, formatting for publication and author proofing. The American Chemical Society provides "Just Accepted" as a free service to the research community to expedite the dissemination of scientific material as soon as possible after acceptance. "Just Accepted" manuscripts appear in full in PDF format accompanied by an HTML abstract. "Just Accepted" manuscripts have been fully peer reviewed, but should not be considered the official version of record. They are accessible to all readers and citable by the Digital Object Identifier (DOI囚). "Just Accepted" is an optional service offered to authors. Therefore, the "Just Accepted" Web site may not include all articles that will be published in the journal. After a manuscript is technically edited and formatted, it will be removed from the "Just Accepted" Web site and published as an ASAP article. Note that technical editing may introduce minor changes to the manuscript text and/or graphics which could affect content, and all legal disclaimers and ethical guidelines that apply to the journal pertain. ACS cannot be held responsible for errors or consequences arising from the use of information contained in these "Just Accepted" manuscripts. 


\title{
Quantum Chemical Investigation of the Selenite Incorporation into the Calcite (1014) Surface
}

\author{
Robert Polly,* Frank Heberling, Bernd Schimmelpfennig, and Horst Geckeis \\ Karlsruher Institut für Technologie (KIT), Campus Nord, Institut für Nukleare \\ Entsorgung (INE), Postfach 3640, 76021 Karlsruhe, Germany \\ E-mail: polly@kit.edu
}

\begin{abstract}
Selenium is a common pollutant in soils and aquifers. The radioisotope ${ }^{79} \mathrm{Se}$, an abundant fission product of ${ }^{235} \mathrm{U}$, is of particular concern in the context of nuclear waste disposal safety due to its long half-life and its expected high mobility in the multi-barrier system around potential nuclear waste disposal sites. Oxidized selenium species are relatively soluble and show only weak adsorption at common mineral surfaces. However, a possible sorption mechanism for selenium in the geosphere is the structural incorporation of selenium(IV) (selenite, $\mathrm{SeO}_{3}^{2-}$ ) into calcite $\left(\mathrm{CaCO}_{3}\right)$.

We carried out a detailed quantum chemical study of the incorporation of $\mathrm{SeO}_{3}^{2-}$ into the calcite surface and the subsurface layers.
\end{abstract}

As the main result we present the structural changes upon incorporation of selenite

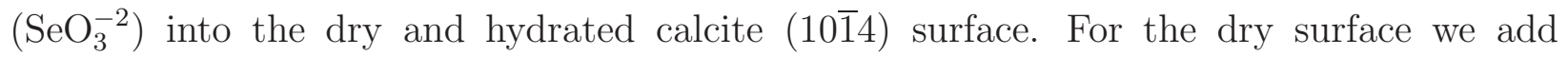
results for the incorporation into the subsurface layers. This results are complemented by energetic considerations and in turn used to estimate the thermodynamic partition 
coefficient $\mathbf{D}$ for $\mathrm{SeO}_{3}^{-2}$ incorporation into the surface and subsurface layers. The results corroborate the recently proposed entrapment model for selenium(IV) coprecipitation with calcite and show that equilibrium incorporation of selenite into calcite may occur in the surface layer, but is practically impossible in subsurface layers or the bulk. 


\section{Introduction}

An important aspect of the civil use of nuclear power is the safe disposal of the radioactive waste. Notably highly radioactive waste with long-lived components has to be isolated safely from the biosphere over geological periods of time. In case of gradual water intrusion into the repository corrosion of container and waste forms as well as mobilization of radionuclides might occur. In safety assessments it needs to be shown that subsequent transport radionuclides to the biosphere is negligible. ${ }^{1,2}$

Sorption at mineral surfaces can significantly reduce the migration rate of radionuclides in the geosphere. Therefore, sorption reactions of radionuclides at mineral/water interfaces have to be studied and understood in detail, see ${ }^{3-18}$ and references therein.

Due to two aspects, the radioisotope ${ }^{79} \mathrm{Se}$ is of special concern: its long half-life $\left(3.27 \cdot 10^{5} \text { a }\right)^{19}$ and the expected high mobility. Selenite $\left(\mathrm{SeO}_{3}^{2-}\right)$ anions are retarded only weakly by common mineral surfaces. Therefore, ${ }^{79}$ Se has been identified as a potentially dose dominating fission product in long term safety assessment calculations for nuclear waste repositories $\left(\mathrm{see}^{20}\right)$.

Calcite is the most common polymorph of calcium carbonate. In the geological environment of potential nuclear waste disposal sites calcite is present as a mineral constituent in clay formations (up to $20 \%$ ), as fracture filling material in granitic rocks, or as a corrosion product of concrete based materials in the technical barrier. A recent joint theoretical and experimental study by Aurelio et al. ${ }^{21}$ showed that selenite can be incorporated into bulk calcite. But, to our knowledge, no theoretical data addressing the incorporation of selenite $\mathrm{SeO}_{3}^{2-}$ into the calcite surface and subsurface layers is available.

Therefore we attempted these first principle calculations tackling the incorporation of selenite into the calcite surface layer from a theoretical perspective and provided 
theoretical structural as well as energetic information supporting and explaining recent experimental results by Heberling et al. ${ }^{18}$

Overall, there is a large number of theoretical studies targeting calcite, see ${ }^{21-41}$ using either force-field methods or employing density functional theory (DFT). ${ }^{42-44}$ There are numerous experimental studies investigating various aspects of the calcite(1014)/water interface as well. ${ }^{18,45-53}$

In our work we aimed for an improved theoretical understanding of the incorporation mechanism of selenium into calcite surface layers similar as carried out in an earlier experimental work by Heberling et al. ${ }^{18}$ Hence we studied the incorporation of selenium into bulk calcite, similarly as had been done by Aurelio et al. ${ }^{21}$ But we extended this study by investigation how selenium is incorporated into the surface and subsurface layers of the calcite (1014) surface. For this we used different models for the dry and hydrated calcite surface allowing an additional view on the influence of surface water. We studied in a first step the calcite bulk phase (without selenite) and the calcite (10̄14) surface without (dry) and in contact with water (hydrated). The scope and methodology of this first part of the paper is similar to the theoretical work of Lardge et $a{ }^{29-31}$ In their work they had focused mainly on the sorption of one or a few water molecules on the surface addressing the question whether the sorption of water

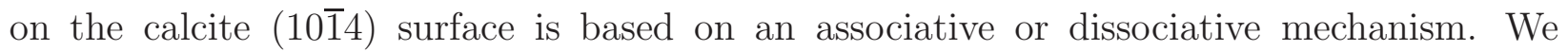
put an emphasis on the structural changes of pure calcite from the dry surface to the hydrated surface induced by the presence of water as well as the arrangement of the water layers adjacent to the surface. In the second part we studied the structural changes upon incorporation of selenite into the bulk phase and the dry and hydrated (10̄14) surface of calcite. Additional to the structural information we provide results about the energetic changes upon incorporation of selenite $\mathrm{SeO}_{3}^{2-}$ into the bulk, the (1014) surface and subsurface layers and provide new information complementing the 
results of Heberling ${ }^{18}$ et al..

For this work we compared our results with the already available theoretical and experimental data of Aurelio et al., ${ }^{21}$ Lardge et al., ${ }^{29-31}$ Cheng et al. ${ }^{45}$ Geissbühler et al. ${ }^{47}$ Heberling et al. ${ }^{18,49}$ and Fenter et al. ${ }^{50,51}$ These studies have a similar focus as ours and provide a broad range of theoretical and experimental data to assess the accuracy of our results. This is important to ensure the accuracy of our results in every step of this work.

The paper is organized as follows: in section 2 we briefly describe the employed quantum chemical methodologies. The results of the considered pure calcite systems are presented in section 3.1 and the results for the incorporation of selenite into calcite are described and discussed in section 3.2.

\section{Computational details}

For the calculation we used $\mathrm{DFT}^{42,43}$ with periodic boundary conditions (PBC) as implemented in the Vienna Ab Initio Simulation Package (VASP). ${ }^{54-56}$ The Kohn-Sham equations were solved using a plane-wave basis set. Electron exchange and correlation were described using the Perdew-Burke-Ernzerhof (PBE) version ${ }^{57}$ of the generalized gradient approximation (GGA). The ion cores were described by projector augmented wave (PAW) potentials ${ }^{58}$ as implemented by Kresse and Joubert. ${ }^{59}$

We employed an energy cutoff of $500 \mathrm{eV}$ for the kinetic energy of the plane waves for all bulk and surface calculations and the determination of the lattice parameters for bulk calcite. For the surface calculations on the dry and hydrated calcite (10̄14) surface we performed calculations with restrictions ${ }^{1}$ applied to the lowest layers of

\footnotetext{
${ }^{1}$ We applied the restriction to keep the lowest two layers fixed at their bulk values or to lifted this restriction and allowed the lowest two layers to be completely optimized in the surface calculations. 
calcite in order to study their influence on the surface structure.

\subsection{Bulk structure and dry surface optimization}

The first step is to determine the lattice parameters of bulk calcite. For this task we used a monoclinic and the hexagonal unit cell (see Fig. 1a and b). The choice of a monoclinic cell is infrequent for bulk calculations, but we chose a monoclinic unit

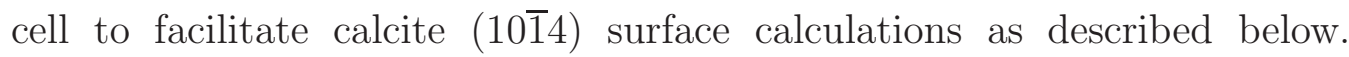

But in order to compare with the results of the hexagonal unit cell which is usually used for the calculations we caried out calculations with both unit cells. Note that

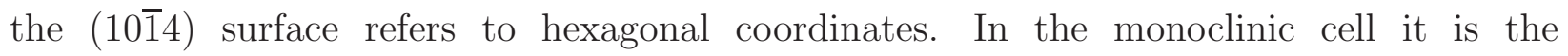
(001) surface, still we will keep calling it (10̄14) surface for the sake of simplicity.

Based on the optimized bulk structure we determined the geometry of the dry calcite (1014) surface in contact with vacuum as shown in Fig. 2. Our surface model is based on a 2x2x2 supercell of monoclinic shape consisting of five $\mathrm{CaCO}_{3}$ layers, whose

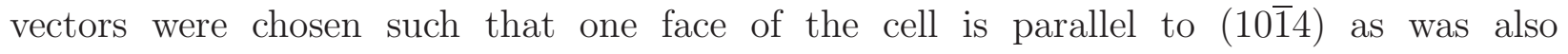
used by Heberling et al. ${ }^{49}$ As can be seen from Fig. 2 we were restricted to this quite small model of the surface, because of the computational limitations when introducing the three layers of water on top of the surface. Thus we did not focus on surface rumpling or local variations of the surface in great detail, since for this purpose the chosen surface model should be larger.

In the model we introduced a vacuum layer of $15 \AA$ between slabs, which we tested to be sufficient such that the calcite slabs were isolated from its periodic images. For the initial relaxation of the structures, we used the real-space evaluation of the PAW projection operators. ${ }^{60}$

The bulk lattice parameters were calculated by looping over the volume and relaxing 


\subsection{Hydrated surface}

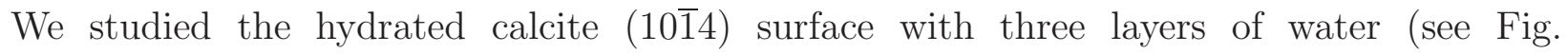
3). These calculations allowed a direct theoretical study of the structure of water

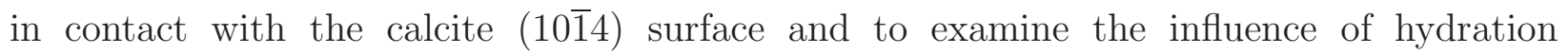
water on the surface structure.

Here it should be emphasized that for the hydrated surface we do only "static" DFT calculations optimizing the structure. In the literature, see, ${ }^{29-31}$ these calculations are called static optimizations compared to efforts explicitely including the motion of the involved species, as in molecular dynamic (MD) calculations. There are a lot of local energetic minima and almost certainly we did not find the global minimum. But we know from previous studies that the local minima ${ }^{14,61}$ have physical properties very close to each other and to the global minimum. Thus the properties derived from the local minima are a fair representation of the system for our purpose.

In the calcite surface layer we had eight positively charged calcium ions $\left(\mathrm{Ca}^{2+}\right)$ and eight negatively charged carbonate groups $\left(\mathrm{CO}_{3}^{2-}\right)$ with different electrostatic interaction with hydration water. Accordingly, we placed eight water molecules on top of the 
calcium ions and eight on top of the carbonate groups in agreement with previous crystal truncation rod measurements ${ }^{47,49}$ and computational ${ }^{26,33}$ studies. Thus we had $8+8=16$ water molecules in the first two layers. These two layers had quite similar average distances from the surface and the water molecules form bonds with the surface. Initially no preferred ordering of the first and second water layer was assumed.

On top of these two layers we added a third layer, consisting of 15 initially orderless water molecules. This third layer was intended to simulate the effect of bulk water on the first two layers, as motivated by our earlier work on corundum (Janecek et $\left.a l .{ }^{61}\right)$. The geometry of the whole structure (surface plus three water layers) was optimized in turn.

\subsection{Incorporation of selenite $\mathrm{SeO}_{3}^{2-}$ into the bulk phase and sur- face}

For the bulk calculations we used the monoclinic and hexagonal unit cell. In the monoclinic cases we substituted one $\mathrm{SeO}_{3}^{2-}$ in a $2 \times 2 \times 2$ super cell (see Fig. 4) and in the hexagonal case in a 2x2x1 super cell (see Fig. 5). The challenge of these calculations originated from the different structures of the $\mathrm{CO}_{3}^{2-}$ and $\mathrm{SeO}_{3}^{2-}$ ions. The former having a planar and the latter a pyramidal shape which induces a large strain to the lattice upon incorporation.

The calculations dealing with the incorporation of selenite into the surface layer were carried out with the dry and hydrated surfaces of the monoclinic 2x2x2 cell (see Fig. 6). In both cases a surface $\mathrm{CO}_{3}^{2-}$ group was replaced by a $\mathrm{SeO}_{3}^{2-}$ group. 


\section{Results}

\subsection{Bulk structure and surface optimization of pure calcite}

\subsubsection{The bulk structure}

Results of the optimization of the monoclinic and hexagonal unit cell (see Fig. 1) are summarized in Table 1. In Table 1 we compare our calculated values with the experimental crystal structure ${ }^{62,63}$ and the theoretical results of the force field calculations of Demichelis et al. ${ }^{37}$ (see Table 2 in $^{37}$ for the theoretical results, the experimental values at $\mathrm{T}=298 \mathrm{~K}$ and the extrapolation of the experimental data to $\mathrm{T}=0)$.

As can be seen from Table 1 all calculated distances are slightly longer compared to the experimental values. This is an intrinsic deviation of DFT and should be expected. The errors are sufficiently small across all calculated values (with one exception) with a relative error smaller than $1.6 \%$. Only the theoretical value for $c$ in the hexagonal case deviates by $4.3 \%$.

An intrinsic issue with DFT is the absence of a proper description of long range dispersion contributions. ${ }^{64}$ Hence we tested to which extent the inclusion of dispersion would improve this result by means of the van der Waals correction DFT-D2/D3 method by Grimme ${ }^{65,66}$ and did this for both unit cells. As can be seen from Table 1 for D2 only $c$ (for the hexagonal unit cell) is slightly reduced to $1770 \mathrm{pm}$ (deviation from the experimental result 3.8\%) but remains unaltered for D3. All other values remain constant within significant digits. This shows that the inclusion of dispersion is not important for the description of the bulk phase as already pointed out by Klimež et $a l .{ }^{67}$. Nevertheless we include this in our work for the subsequent description of the hydrated surface. 


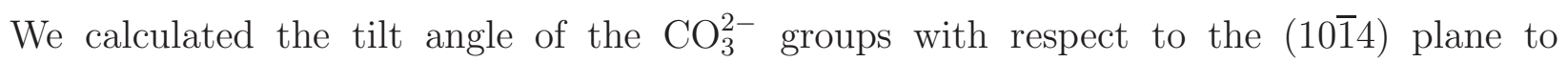
be $44.6^{\circ}$. This agrees very well with the experimental value of $44.7^{\circ} .49,50$

For the charges we applied Bader Charge Analysis. ${ }^{68}$ In Table 2 we list the Bader charges of the involved ions for the bulk and the different surface calculations. The results $\left(\mathrm{q}_{C a^{2+}}=1.652, q_{O^{2-}}=-1.136\right.$ and $\left.q_{C^{4+}}=1.757\right)$ agree very well with the expected charges of the ions. We list them here as reference values for following surface calculations.

Due to the good agreement of the calculated results with the available experimental values $^{49,62,63}$ we fixed the calculation parameters, like the energy cut off, the number of k-points, the functional or other parameters used by VASP. Explicit test calculations increasing the number of $\mathrm{k}$-points to $5 \times 5 \times 5$ (bulk) and $5 \times 5 \times 1$ (surface) showed that the variation of the electronic energy is $<1 \mathrm{meV}$ and negligible.

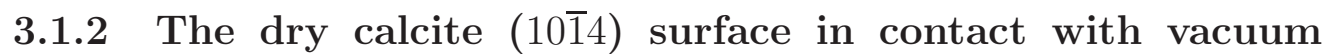

Only, the optimized monoclinic unit cell was used to further explore the calcite (10̄14)

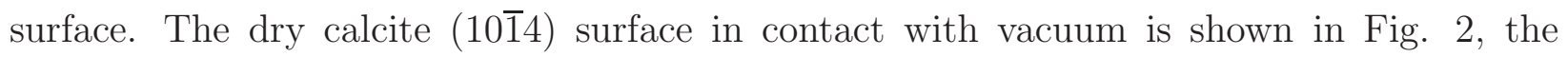
results are summarized in Table 3. Here and in the following sections, the positions of the surface calcium atoms define the location of the surface. We carried out two different calculations fixing the lowest two of the five layers $\left(4^{\text {th }}\right.$ and $5^{\text {th }}$ layer in Fig. 2) to their bulk values or without this restriction. As can be clearly seen from the numbers in Table 3 fixing the lowest two layers had basically no influence on the resulting surface structure.

Overall there are many small changes from the bulk to the surface structure. The interlayer distance between the first and second $\mathrm{Ca}$ layers shrinks from $306 \mathrm{pm}$ in the bulk phase to $d_{(10 \overline{1} 4), C a-C a}=298 \mathrm{pm}$ but within the surface layer the $r_{C a-C a}$ distance remains unchanged at $409 \mathrm{pm}$. Consequently the $r_{\mathrm{Ca}-\mathrm{Ca}}$ from the first to 
the second layer are shortened The $r_{C a-C}$ distances split up from a sharp value of 325 for bulk calcite to several different values of $323,325,329$ pm or $322,325-326,329$ without and with restriction applied, respectively. Similarly the $r_{C a-O}$ distances are altered from a sharp 239 (bulk) to a range of 231 and $238-240 \mathrm{pm}$. The $r_{C-O}$ distances are modified from 130 (bulk) to $128-132$ pm. Besides the strong reduction of the first interlayer distance from 306 to $298 \mathrm{pm}$ the structure of the first layer is only slightly altered relative to the bulk values. $\mathrm{CO}_{3}^{2-}$ groups of the first layer are in average tilted by $3.4 \pm 0.2^{\circ}$ compared to their bulk values. The angle between the plane defined by the $\mathrm{Ca}$ atoms and the plane of the $\mathrm{CO}_{3}^{2-}$ ions are decreased from $44.6^{\circ}$ to $41.2^{\circ}$ (without restriction) and $42.1^{\circ}$ (with restrictions). The influence of the applied restrictions on the surface structure is negligible regarding the bond distances and very small regarding the tilt angle. For the case without restrictions we tested additionally the influence of the dispersion correction ${ }^{65}$ and find no influence on the structure. Obviously, the missing Ca-O bonds $(239 \mathrm{pm})$ on the surface reduce the tilt angle of the $\mathrm{CO}_{3}^{2-}$ groups. This is a likely cause for the reduction of the interlayer distance between the first and second Ca layers from 306 pm to $298 \mathrm{pm}$.

In Table 2 we list the Bader charges of the involved ions for the dry surface calculations. We did these calculations only for the dry surface, since the hydrated surface would require more $\mathrm{CaCO}_{3}$ layers in our model system. We find that all layers are neutral but the differences between the positively charged ions decrease when approaching the surface. The results for the first, second and third layer smoothly approach the value of the bulk phase. But for more accurate and reliable results the model system should contain more $\mathrm{CaCO}_{3}$ layers. 


\subsubsection{The hydrated calcite (10̄14) surface}

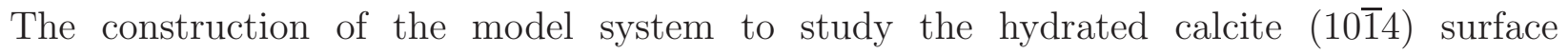
was described above in subsection 2.2 (see also Fig. 3). We focus on two results, (1) the modification of the first $\mathrm{CaCO}_{3}$ surface layer induced by the presence of hydration water and (2) the distances of the first and second water layer to the surface. The results are summarized in Table 4.

First of all it is remarkable that the interlayer distance between the first and second Ca layer was restored close to the bulk value at $d_{(10 \overline{1} 4), C a-C a}=308$ (303) pm without and with dispersion correction. We arrived at this result although we used in both cases the dry surface $\left(d_{(10 \overline{1} 4), C a-C a}=298 \mathrm{pm}\right)$ as the starting geometry for the surface and added the 31 water molecules to this initial surface structure. After a few iterations the final value for the interlayer distance between the surface layer and the second layer of 308 (303) pm was established (calculated value for the bulk phase 306 (304) $\mathrm{pm})$.

This is in very good agreement with the experimental results of Geissbühler et al. ${ }^{47}$ and Heberling et al. ${ }^{49}$. For the same surface they found an interlayer spacing of $306 \mathrm{pm}$ which is larger compared to the experimental bulk value of $304 \mathrm{pm}$. But our result does not fit so well with the recent results of Fenter and Sturchio (294 pm $)^{50}$ and Heberling et al. $(297 \mathrm{pm}) .{ }^{52}$ These results are closer to our result of the dry surface. It is of interest to note that in comparison to this newer experimental data the addition of the dispersion correction improved the result.

Overall the internuclear distances in the surface layer are strongly modified due to the presence of water and the bonds formed between the surface and the first two water layers. The $r_{C a-C a}$ distances vary from 402 to $416 \mathrm{pm}$, the $r_{C a-C}$ distances from 315 to $334 \mathrm{pm}$ and the $r_{C a-O}$ distances from 235 to $242 \mathrm{pm}$. Only the changes of the $r_{C-O}$ distances are very small, they range from 129 to $131 \mathrm{pm}$, which is comparable 
to the dry surface. This modification can be explained by the interaction and the bonds of the water molecules adjacent to the surface with surface atoms of the calcite surface. The order at the surface is disturbed by the less ordered first and second water layers due to the formation of water-to-surface bonds.

The tilt angle of the $\mathrm{CO}_{3}^{2-}$ groups are modified and range from $50.9^{\circ}$ to $57.1^{\circ}$ $\left(50.1^{\circ}\right.$ to $\left.56.0^{\circ}\right)$ (measured in reference to the plane of the Ca atoms). The average value is an increase of the tilt angle from $44.6^{\circ}$ (bulk) to $54.2^{\circ}\left(53.1^{\circ}\right.$ ). This is in good agreement with the experimental result of Heberling et $a l .{ }^{49}$ and by Fenter and Sturchio. ${ }^{50}$ Heberling et $a l .{ }^{49}$ report an increase of the tilt angle by $6.9^{\circ}$ in the same direction as we found and a high Debye-Waller factor pointing at a large variation of the tilt angle. Very close to this result Fenter and Sturchio reported $50.3^{\circ}$.

The tilt angle is larger for the hydrated surface compared to the dry surface. Furthermore, more bonds are formed between the surface and the first two water layers. In total this results in an increased interlayer spacing compared to the dry surface and the bulk values.

The average distances of the water molecules from the surface are listed in Table 4. Initially the water molecules of all three layers are arbitrarily oriented above the

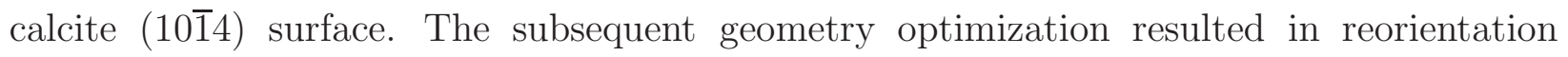
of the water molecules. A well-ordered structure of the first two water layers is thus obtained since these water molecules strongly interact with either the $\mathrm{Ca}^{2+}$ ions (first layer) or the $\mathrm{CO}_{3}^{2-}$ groups (second layer). Calling the structure of the first two layers well ordered has two aspects: (1) the orientation of the molecules and (2) the distance from the surface.

The orientation of the water molecules follows the arrangement of the surface. On top of the $\mathrm{Ca}^{2+}$ ion we find water molecules with the oxygen oriented towards the surface $\mathrm{Ca}^{2+}$ ion and both $\mathrm{OH}$ bonds oriented almost parallel to the surface. For 
the negatively charged $\mathrm{CO}_{3}^{2-}$ groups the situation is reversed as should be expected. The water molecules close to the $\mathrm{CO}_{3}^{2-}$ groups point with one hydrogen towards the surface. This orientation of the water molecules is similar to the orientations found by Raiteri et al. ${ }^{33}$ using force-field calculations.

We define the water position as the position of the oxygen atom and the surface plane as the average position of the surface $\mathrm{Ca}^{2+}$ ions. The results are in very close agreement with the experimental results: ${ }^{49} 242$ vs $245 \mathrm{pm}$ and 316 vs $325 \mathrm{pm}$. The agreement is less satisfactory when including the DFT-D2/D3 dispersion correction: ${ }^{65,66}$ $237 / 238$ vs $245 \mathrm{pm}$ and 305/305 vs $325 \mathrm{pm}$. This unexpected observation is clearly a sign for the short coming of the model. Adding just three water layers is obviously not an adequate model. Inclusion of a fourth or fifth layer would improve the model but increase the time for the optimization of the structure considerably. The maximum deviation of the water layer distance from the surface (without dispersion correction) is $242 \pm 14 \mathrm{pm}, 316 \pm 17 \mathrm{pm}$ and $562 \pm 71 \mathrm{pm}$, respectively. This shows that the first and second layer are quite well defined as can be seen by the small standard deviation of the mean values (14 and $17 \mathrm{pm})$, but the third layer shows significantly less ordering $(71 \mathrm{pm})$. Hence the third layer serves as a minimal model system for bulk water. Restricting the bottom layer of the calcite slab to the bulk structure has no influence on the structure of the hydrated surface or the positions of the hydration water.

The distance between the Ca atoms of the first layer and the oxygen atoms of the water molecules range from 243 to $255 \mathrm{pm}$. This compares very well to the theoretical results of Lardge et al. ${ }^{29,30}$ (237 pm), De Leeuw and Parker ${ }^{22,22}$ (240 pm) and Wright et $a l .{ }^{69}(250 \mathrm{pm})$ for one monolayer of water on top of the surface. There is an offset in the xy plane of the water molecules of the first layer compared to the top most Ca layer. Hence the Ca-O bonds are longer compared to the interlayer distanced between the surface layer and the first water layer. 
The lateral displacement of the oxygen atoms is in x-direction between 19 and $73 \mathrm{pm}$ and in y-direction between 10 and $42 \mathrm{pm}$. The displacement of the water molecules in the $\mathrm{x}$-direction does not follow the tilt of the $\mathrm{c}$ axis of calcite (tilted by $17.6^{\circ}$ towards the z-axis, see Fig. 6) but points into the opposite direction.

Finally the water molecule coordination to the surface calcium ions (surface layer) restore, together with the carbonate ions of the surface and the first subsurface layer, a close to perfect coordination octahedron around the surface calcium ions.

For the intramolecular $\mathrm{OH}$ distances we found values in the range between 97 and 103 pm. The intermolecular $\mathrm{OH}$ distances are either water-water or water-surface bonds. For the water-water intramolecular $\mathrm{OH}$ distances we found values from 155 to 215 pm and for the water-surface $\mathrm{OH}$ bonds values ranging between 162 and $176 \mathrm{pm}$.

Thus we see that the chosen theoretical framework provides data very well in agreement with accessible experimental results for the considered pure calcite systems This underlines the soundness of the applied theoretical approach and strongly supports the following study of the incorporation of selenite $\mathrm{SeO}_{3}^{2-}$ into calcite.

\subsection{Incorporation of selenite $\mathrm{SeO}_{3}^{2-}$ into the bulk phase and (10̄14) surface of calcite}

\subsubsection{Incorporation of selenite $\mathrm{SeO}_{3}^{2-}$ into the bulk phase of calcite}

The incorporation of $\mathrm{SeO}_{3}^{2-}$ into the calcite bulk phase by replacing a $\mathrm{CO}_{3}^{2-}$ was studied using the monoclinic (see Fig. 4) and the hexagonal unit cell (see Fig. 5). Technically it was easier to do these calculations with the hexagonal cell, due to the presence of the $\overline{3}$ symmetry axis. If only the substitution into the bulk phase would be considered here we would only use the hexagonal cell as Aurelio et $a .^{21}$ did. But

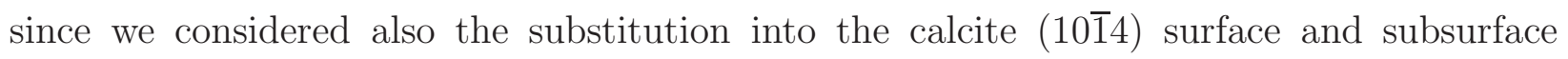


layers and compare with data obtained by Heberling et al. ${ }^{18}$ at this surfaces we had to use the monoclinic cell as well.

The incorporation of pyramidal $\mathrm{SeO}_{3}^{2-}$ into $\mathrm{CaCO}_{3}$ poses some sterical challenges as pyramidal $\mathrm{SeO}_{3}^{2-}$ replaces a planar $\mathrm{CO}_{3}^{2-}$. In the gas phase model of $\mathrm{SeO}_{3}^{2-}$ the Se atom is located $65 \mathrm{pm}$ above the plane defined by the three oxygen atoms and has a pyramidal shape as already determined by Wickleder ${ }^{70}$ for $\mathrm{Na}_{2} \mathrm{SeO}_{3}$. The three Se-O bonds are $169 \mathrm{pm}$ long as determined with MP2/def2-TZVPP gas phase calculations using TURBOMOLE. ${ }^{71-77}$

The determination of the structure of $\mathrm{SeO}_{3}^{2-}$ incorporated into $\mathrm{CaCO}_{3}$ with both unit cells yield almost identical results. The Se-O bond lengths are 173 (172) pm and the Se atom is located 75 (73) pm above the plane defined by the three oxygen atoms (see Fig. 7) for the monoclinic and hexagonal unit cell. The result for the hexagonal cell is in full agreement with the result reported by Aurelio et al. ${ }^{21}$ The Se-O bond lengths are longer upon incorporation of $\mathrm{SeO}_{3}^{2-}$ into calcite compared to the gas phase values, because here the oxygen ions are charged less negative compared to the gas phase. This is quite close to the result $(168 \mathrm{pm})$ of Heberling et al. ${ }^{18}$ The optimization was completely straight forward using the hexagonal unit cell, but we ran into some problems using the monoclinic unit cell. For the monoclinic unit cell we proceeded in two steps. First we moved the $\mathrm{Se}^{4+}$ slightly out of the oxygen plane and optimized only the $\mathrm{SeO}_{3}^{2-}$ structure keeping the whole rest of the unit cell, consisting of the surrounding calcite structure, fixed. Upon fully relaxing the $\mathrm{SeO}_{3}^{2-}$ we optimized in a second step the whole unit cell.

For the hexagonal cell we found that the three oxygen atoms of $\mathrm{SeO}_{3}^{2-}$ are moved out of the plane defined by the $\mathrm{CO}_{3}^{2-}$ groups by $6 \mathrm{pm}$ in the opposite direction of the Se atom which sits $68 \mathrm{pm}$ above of this plane. This is not in agreement with the earlier theoretical results of Aurelio et $a .^{21}$ where they found that these oxygen 
atoms remain in the plane of the original $\mathrm{CO}_{3}^{2-}$ group (see Fig. 7). The reasons for this discrepancy could be the much smaller plane wave cut off of $280 \mathrm{eV}$ used in their work. In the monoclinic case we compare the position of the Se with the plane defined by the Ca atoms and found that it is located $48 \mathrm{pm}$ above this plane.

The local effects of the incorporation of $\mathrm{SeO}_{3}^{2-}$ on the ion-ion distances for the monoclinic and hexagonal cell are listed in Table 5. Overall the results of the calculations with the monoclinic and hexagonal cell are very similar.

For the $\mathrm{r}_{C a-C a}$ we find strong modifications from the pure calcite values in the vicinity of the $\mathrm{SeO}_{3}^{2-}$ substitution. In the first shell around the $\mathrm{SeO}_{3}^{2-}$ substitution the $\mathrm{r}_{C a-C a}$ are increased from the distances of pure calcite $(409$ and $505 \mathrm{pm})$ to $416-423$ $(414-424)^{2} \mathrm{pm}$ and up to $544-545$ (549) for the longer distance. But the distortion causes also some of the longer Ca-Ca bonds to shrink and they can be found in the region $496-510(499-500) \mathrm{pm}$. In the second shell the shorter distances are found in the region $398-415(398-410)$ and the longer distances in the region $467-488$ (466) and 503-511 (505-516) pm. As a summary we see that Ca-Ca distances in the first shell are increased whereas they are decreased in the second shell. Hence, locally the modifications of the ion-ion distances are quite large, but further away from the substitution, the Ca-Ca distances are close to the values of pure calcite.

Only small variations of the ion-ion distances are found between both sets of calculations using the monoclinic and hexagonal cells. This shows the reliability of our approach since the more demanding calculations based on the monoclinic cell provided results very close to the calculations with the hexagonal cell.

\footnotetext{
${ }^{2}$ In brackets we list the results for the calculations with the hexagonal cell.
} 


\subsubsection{Incorporation of selenite $\mathrm{SeO}_{3}^{2-}$ into the dry (1014) surface and sub- surface layers of calcite}

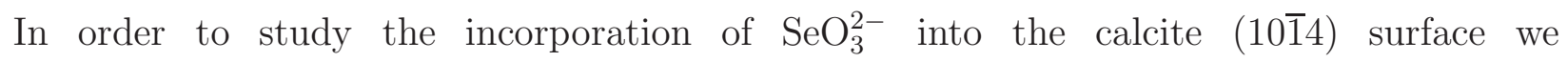
performed calculations with the monoclinic cell only. Here a $\mathrm{SeO}_{3}^{2-}$ replaced a $\mathrm{CO}_{3}^{2-}$ in the surface, second or third layer as shown in Fig. 8. The results are summarized in Table 6.

We find that the structure of the $\mathrm{SeO}_{3}^{2-}$ itself is hardly changed when incorporated into the surface. The $\mathrm{SeO}_{3}^{2-}$ group at the surface is slightly distorted with two Se-O bond lengths at $175 \mathrm{pm}$ and one at $170 \mathrm{pm}$. Se is lifted by $75 \mathrm{pm}$ from the oxygen plane (denoted as 1 in Fig. 9) and is located $92 \mathrm{pm}$ above the plane of the Ca atoms (denoted as 2 in Fig. 9).

The Ca-Ca distances within (409 and $505 \mathrm{pm}$ ) the surface layer vary are 419/427 and $499 / 544 \mathrm{pm}$ for the four $\mathrm{Ca}^{2+}$ ions in the vicinity of the $\mathrm{SeO}_{3}^{2-}$ group. Hence there is a strong distortion of calcite around the $\mathrm{SeO}_{3}^{2-}$. The distance to the $\mathrm{Ca}$ ions of the second layer is altered as well. These distances around the substitution are $395-403 \mathrm{pm}$. They are smaller compared to the values of pure calcite, because for the dry surface the interlayer distance to the first sublayer is decreased.

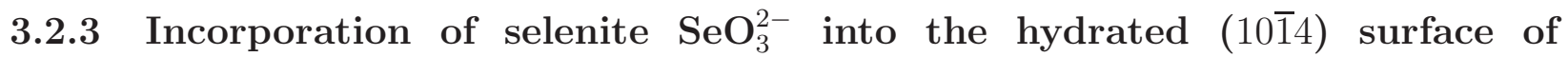 calcite}

There are eight $\mathrm{CO}_{3}^{2-}$ groups in the surface layer. For the hydrated surface we probed all eight different possibilities and substituted only one $\mathrm{CO}_{3}^{2-}$ by $\mathrm{SeO}_{3}^{2-}$ in all these eight different positions and carried out a full optimization of the surface and the complete water layer (see Fig. 6). The total electronic energy of the different probed replacement positions varies by less than $0.2 \mathrm{eV}$. This effect is mainly due to the presence and relaxation of the water molecules in the first and second water layer. 
The Se-O bonds range between 172 and $174 \mathrm{pm}$ (see Table 6) and the Se atom is lifted between 67 and $79 \mathrm{pm}$ above the Ca plane (denoted as 2 in Fig. 9) which is larger compared to the bulk phase but is slightly smaller compared to the dry surface. If we look at the displacement of the Se atom compared to the plane defined by the three oxygen atoms of the $\mathrm{SeO}_{3}^{2-}$ species (denoted as 1 in Fig. 9) we find a very similar value of $75-76(63 \pm 11)^{45} \mathrm{pm}$ which compares well to the numbers presented above for the bulk phase and the dry surface. For the hydrated surface the top most oxygen atom of the $\mathrm{SeO}_{3}^{2-}$ is located $79(54 \pm 6)^{45} \mathrm{pm}$ above the Ca plane compared to 67 for the $\mathrm{CO}_{3}^{2-}$ group. Hence, our results compare quite well with the results reported by Cheng et al. ${ }^{45}$ There, the top most oxygen atom sits at $81 \mathrm{pm}$ above the same plane. Looking at the structure of $\mathrm{SeO}_{3}^{2-}$ in the second and third layer we can see, that it has almost the same structure as when incorporated into bulk.

The distances $\mathrm{r}_{C a-C a}$ vary from 395 to $411 \mathrm{pm}$ between the first and second layer. Looking at the four distances between the four $\mathrm{Ca}^{2+}$ ions in the surface plane around the $\mathrm{SeO}_{3}^{2-}$ substitution we find distances of 426, 494 and $538 \mathrm{pm}$. Since the interlayer distance between the surface and second layer is increased due to the presence of water the distances of the $\mathrm{Ca}^{2+}$ ions to the second layer are increased as well, compared to the dry surface.

The distances $\mathrm{r}_{C a-S e}$ vary from 335 to $379 \mathrm{pm}$. Hence the modifications in the hydrated surface are very similar to the dry surface. The results are summarized in Table 6.

The first and second water layers are hardly affected by substituting a $\mathrm{CO}_{3}^{2-}$ by a $\mathrm{SeO}_{3}^{2-}$ group. Only the water molecule sitting on top of the $\mathrm{SeO}_{3}^{2-}$ is moved $25 \mathrm{pm}$ away from the surface. 


\subsubsection{Energy cost of incorporating $\mathrm{SeO}_{3}^{2-}$ into the bulk, as well as the surface and subsurface layers}

In this part of our work, we considered the reaction energies calculated from the electronic energies as a reasonably good approximation for the Gibbs free energy $(\Delta G \approx \Delta E)$.

In order to study the energy changes (see eq. (10) to (16) in Heberling et al. ${ }^{18}$ ) for different cases of substitution we look at the reactions

$$
\left[\mathrm{Ca}\left(\mathrm{CO}_{3}\right)\right]_{m}+\left[\mathrm{CaSeO}_{3}\right] \rightarrow \mathrm{Ca}_{m}\left(\mathrm{CO}_{3}\right)_{(m-1)} \mathrm{SeO}_{3}+\left[\mathrm{CaCO}_{3}\right]
$$

m indicates the number of $\mathrm{Ca}^{2+}$ and $\mathrm{CO}_{3}^{2-}$ ions in the supercell. Reaction (1) indicates that one of $\mathrm{m} \mathrm{CO}_{3}^{2-}$ anions in the supercell is replaced by one $\mathrm{SeO}_{3}^{2-}$ anion. The number of ions in the bulk is $m_{\text {bulk }}=32$ and for the surface $m_{\text {surface }}=40$.

We determined the corresponding reaction energies

$$
\begin{aligned}
\Delta G_{\text {incorp }, \text { bulk }}= & E_{\mathrm{Ca}_{m}\left(\mathrm{CO}_{3}\right)_{(m-1)} \mathrm{SeO}_{3}}^{\text {bulk }}+E_{\mathrm{CaCO}_{3}}-E_{\mathrm{Ca}_{m}\left(\mathrm{CO}_{3}\right)_{m}}^{\text {bulk }}-E_{\mathrm{CaSeO}_{3}} \\
\Delta G_{\text {incorp } \text { surface }(n)}= & E_{\mathrm{Ca}_{m}\left(\mathrm{CO}_{3}\right)_{(m-1)} \mathrm{SeO}_{3}}^{\text {surface }(n)}+E_{\mathrm{CaCO}_{3}}-E_{\mathrm{Ca}_{m}\left(\mathrm{CO}_{3}\right)_{m}}^{\text {surface }}-E_{\mathrm{CaSeO}_{3}} \\
& n=1,2,3
\end{aligned}
$$

with

$$
\begin{aligned}
E_{\mathrm{CaCO}_{3}} & =\frac{1}{m} E_{\mathrm{Ca}_{m}\left(\mathrm{CO}_{3}\right)_{m}}^{\text {bulk }} \\
E_{\mathrm{CaSeO}_{3}} & =\frac{1}{m} E_{\mathrm{Ca}_{m}\left(\mathrm{SeO}_{3}\right)_{m}}^{\text {bulk }}
\end{aligned}
$$

$E_{\mathrm{Ca}_{m}\left(\mathrm{CO}_{3}\right)_{m}}^{b u l k}$ and $E_{\mathrm{Ca}_{m}\left(\mathrm{SeO}_{3}\right)_{m}}^{b u l k}$ are the electronic energies of the respective supercells with $m \mathrm{Ca}^{2+}$ and $\mathrm{CO}_{3}^{2-} / \mathrm{SeO}_{3}^{2-}$ ions. $\mathrm{n}$ in eq. (3) refers to the surface layer $(\mathrm{n}=1)$, 
or the second or third layer $(\mathrm{n}=2,3) . \quad \mathrm{E}_{\mathrm{CaCO}_{3}}$ and $\mathrm{E}_{\mathrm{CaSeO}_{3}}$ are reasonable reference energies for the bulk calculations. We can use the reaction energies in eq. (2) and (3) to compare the energy changes upon incorporation of $\mathrm{SeO}_{3}^{2-}$ into calcite.

Calculating the energy differences

$$
\begin{aligned}
\Delta \Delta G_{\text {surface }(n)=}= & G_{\text {incorp }, \operatorname{surface}(n)}-\Delta G_{\text {incorp }, \text { bulk }} \\
& (n=1,2,3) .
\end{aligned}
$$

between $\Delta G_{\text {incorp,bulk }}$ and $\Delta G_{\text {incorp,surface(n) }}$ in eq. (2) eq. (3) requires only the knowledge of the surface $\left(E_{\mathrm{Ca}_{m}\left(\mathrm{CO}_{3}\right)_{(m-1)} \mathrm{SeO}_{3}}^{\text {surface }}\right.$ and $\left.E_{\mathrm{Ca}_{m}\left(\mathrm{CO}_{3}\right)_{m}}^{\text {surface }}\right)$ and the corresponding bulk $\left(E_{\mathrm{Ca}_{m}\left(\mathrm{CO}_{3}\right)_{(m-1)} \mathrm{SeO}_{3}}^{\text {and }} E_{\mathrm{Ca}_{m}\left(\mathrm{CO}_{3}\right)_{m}}^{\text {bulk }}\right)$ energies and not the energies $\mathrm{E}_{\mathrm{CaCO}_{3}}$ and $\mathrm{E}_{\mathrm{CaSeO}_{3}}$. Their energy contributions simply cancel out and $\mathbf{D}$ depends only on $E_{\mathrm{Ca}_{m}\left(\mathrm{CO}_{3}\right)_{(m-1)} \mathrm{SeO}_{3}}^{\text {bulk }}, E_{\mathrm{Ca}_{m}\left(\mathrm{CO}_{3}\right)_{m}}^{\text {bulk }}, E_{\mathrm{Ca}_{m}\left(\mathrm{CO}_{3}\right)_{(m-1)} \mathrm{SeO}_{3}}^{\text {urface }()}$ and $E_{\mathrm{Ca}_{m}\left(\mathrm{CO}_{3}\right)_{m}}^{\text {surface }}$ and is independent of the reference states (see eq. (13) in Heberling et al. ${ }^{18}$ ).

Thus by doing this simple calculation we can directly compare the changes of energies upon incorporation of $\mathrm{SeO}_{3}^{2-}$ into the bulk, the surface or subsurface layers of calcite for the different considered cases.

The calculated energies $\Delta G_{\text {incorp,bulk }}$ (2) and $\Delta G_{\text {incorp,surface(n) }}$ (3) for the dry and hydrated surface are shown in Fig. 10. We find that the incorporation energies $\Delta G_{\text {incorp,surface(2) }}, \Delta G_{\text {incorp,surface(3) }}$ and $\Delta G_{\text {incorp,bulk }}$ are higher compared to $\Delta G_{\text {incorp,surface(1). }}$ The incorporation energies $\Delta G_{\text {incorp,surface }(n)} n=1,2,3$ smoothly approach $\Delta G_{\text {incorp,bulk }}$ for the dry and hydrated case and the incorporation into the third layer requires almost the same amount of energy as the incorporation into the bulk phase. For $n=2,3$ the relative incorporation energies for the dry and hydrated case are almost identical and the value of $\Delta G_{\text {incorp,surface(1) }}$ for the hydrated surface does 
not differ a lot from the experimental available result ${ }^{18}$ emphasizing the high quality of our theoretical data. These results show that the incorporation of $\mathrm{SeO}_{3}^{2-}$ into the calcite surface layer is energetically most favorable compared to the incorporation into the subsurface layers or the bulk phase.

These results are consistent with our earlier work ${ }^{18}$ where we showed that selenite is incorporated into the calcite surface and further incorporated into calcite bulk phase by means of a continuous entrapment process.

\section{Discussion}

The incorporation energies calculated according to eq. (2) and (3) may be transformed into excess free energies ${ }^{18}$ (see eq. (10) to (16) therein) and allow to approximate for each layer a thermodynamic partition coefficient D. D, relates the selenite/carbonate ratio in the solid to the selenite/carbonate ratio in the aqueous contact solution, and thus provides a good bases to discuss the practical implication of the layer by layer increase of the incorporation energy. First of all the theoretical partition coefficient for the hydrated surface $(\mathbf{D}=0.005)$ (see Fig. 10) is in fair agreement with the experimentally determined value $\left(\mathbf{D}=0.02 \pm 0.01^{18}\right)$. The subsequent layer by layer increase of the incorporation energy may seem as a smooth transition from the surface towards the bulk. However, looking at the values in terms of partition coefficients, it becomes clear that, while at the surface considerable selenite incorporation is possible $\left(\mathbf{D}_{1^{\text {st layer }}} \approx 10^{-2}\right)$, from the first to the second layer there is a jump in the partition coefficient about seven orders of magnitude $\left(\mathbf{D}_{2^{\text {nd }} \text { layer }} \approx 10^{-9}\right)$, which means that already in the $2^{\text {nd }}$ layer there is practically no more selenite incorporation possible at thermodynamic equilibrium. The further decrease in partition coefficient from $10^{-9}$ to $\approx 10^{-11}$ in layer three and bulk is hardly of practical relevance. The sudden drop in the partition coefficient from the first to the second layer, however, is the key to corroborate 
the previously proposed entrapment mechanism. ${ }^{18}$ Especially the interpretation in terms of entrapment energy, previously used to estimate the supersaturation level, necessary to drive entrapment, gains relevance now as it is demonstrated that the free energy related to a certain surface composition rises abruptly when this surface is buried under an additional layer of calcite.

To briefly reconcile the entrapment model:

1. It is assumed that the surface adopts a certain composition in terms of selenite/carbonate ratio depending of the corresponding solution composition.

2. The supersaturation of the solution may provide a certain driving force for crystal growth.

3. If this driving force is sufficient to provide the incorporation energy for the selenite at the surface to be covered with a new layer of calcite, the crystal grows and selenite is entrapped.

4. If the driving force is not sufficient, the crystal needs to expel selenite in order to grow, which constitutes a considerable kinetic barrier for further crystal growth.

5. At solubility equilibrium conditions, only the topmost monolayer of calcite contributes significantly to selenite sequestration. Any bulk incorporation, due to close to equilibrium recrystallization, as demonstrated for ${ }^{45} \mathrm{Ca},{ }^{78}$ is not expected for selenite in calcite, due to the high energy cost of this process.

\section{Conclusion}

In this work we studied the incorporation of $\mathrm{SeO}_{3}^{2-}$ into the dry and hydrated calcite (10̄14) surface. This work touches a large body of existing theoretical ${ }^{21,29-31}$ and 
experimental $^{18,21,45,47,49-52}$ results focusing on different aspects of the calcite bulk and (1014) surface structure. Aurelio et $a l .{ }^{21}$ studied the incorporation of $\mathrm{SeO}_{3}^{2-}$ using theoretical as well as experimental methods. Lardge et al. ${ }^{21,29-31}$ carried out theoretical studies of the interaction of water with calcite. From the experimental side Geissbühler et al., ${ }^{47}$ Fenter et al. ${ }^{50,51}$ and Heberling et al. ${ }^{18,49,52}$ provide a lot of information about

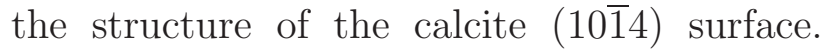

We used all this existing data to assess and gauge the quality of our results. This is an important first step before extending our efforts to the focus of this work, the

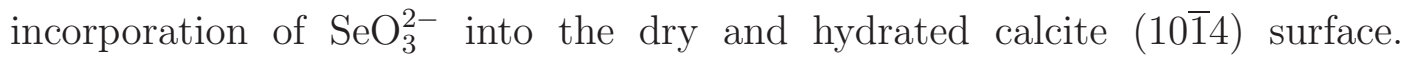

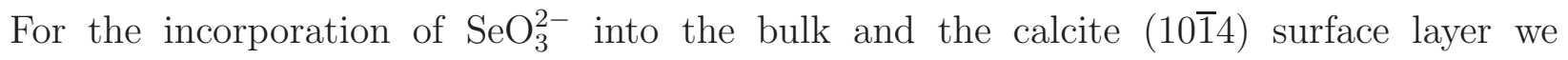
give detailed results of the induced local structural modifications around the $\mathrm{SeO}_{3}^{2-}$ substitution.

Additionally we consider the energies upon substitution of $\mathrm{SeO}_{3}^{2-}$ into the surface and

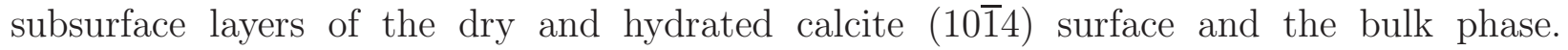
We found that incorporation of $\mathrm{SeO}_{3}^{2-}$ into calcite happens most likely directly at

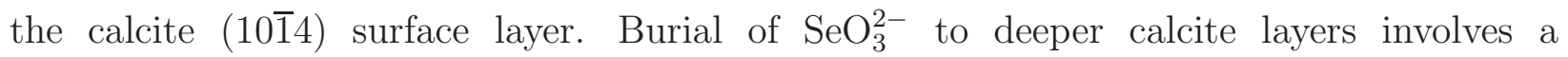
high incorporation energy and is thus only possible at elevated supersaturation (see Heberling et $a .^{18}$ )

The very good agreement of the calculated data with available experimental results shows that "static" DFT calculations can be applied to dynamical systems like the hydrated calcite-water-interface and provide information of broad geochemical significance. Moreover the application of the calculated energies in our previous work in the framework of the Single Defect method (see Heberling et al. ${ }^{18}$ ) confirms the viable information provided by DFT calculations. Hence DFT can be established as a theoretical tool for the investigation of mineral surfaces and in combination with experimental efforts leads to a much better understanding of the considered system. 


\section{Acknowledgment}

We acknowledge funding by the German Federal Ministry for Economic Affairs and Energy (BMWi) through the collaborative project VESPA under grant agreement number 02 E 10800. We would like to thank Hieronymus Sobiesiak and Andreas Benzler (KIT/INE) for their continuous support on the hard and software side. The authors acknowledge support by the state of Baden-Wrttemberg through bwHPC and the German Research Foundation (DFG) through grant no no INST 40/467-1 FUGG.

\section{References}

\section{References}

(1) International Atomic Energy Agency (IAEA), OECD-Nuclear Energy Agency: Geological Disposal of Radioactive Waste. - Safety Requirements, SSR-5. 2008.

(2) OECD-NEA Radioactive Waste Management Committee, Collective Statement on Moving Forward to Geological Disposal of Radioactive Waste, ISBN 978-92-64-99057. 2011.

(3) Geckeis, H.; Lützenkirchen, J.; Polly, R.; Rabung, T.; Schmidt, M. Mineral-Water Interface Reactions of Actinides. Chem. Rev. 2013, 113, 1016.

(4) Stumpf, T.; Hennig, C.; Bauer, A.; Denecke, M. A.; Fanghänel, T. An EXAFS and TRLFS study of the sorption of trivalent actinides onto smectite and kaolinite. Radiochim. Acta 2004, 92, 133.

(5) Rabung, T.; Schild, D.; Geckeis, H.; Klenze, R.; Fanghänel, T. Cm(III) Sorption onto Sapphire $\left(\alpha-\mathrm{Al}_{2} \mathrm{O}_{3}\right)$ Single Crystals. J. Phys. Chem. B 2004, 108, 17160. 
(6) Zhang, Z. et al. Ion adsorption at the rutile-water interface: Linking molecular and macroscopic properties. Langmuir 2004, 20, 4954.

(7) Moskaleva, L. V.; Nasluzov, V. A.; Chen, Z.-X.; Rösch, N. Elastic polarizable enviroment cluster embedding approach for water adsorption on the $\alpha-\mathrm{Al}_{2} \mathrm{O}_{3}(0001)$ surface. A density functional study. Phys. Chem. Chem. Phys. 2004, 6, 4505.

(8) Rabung, T.; Geckeis, H.; Wang, X. K.; Rothe, J.; Denecke, M. A.; Klenze, R.; Fanghänel, T. Cm(III) sorption onto gamma-Al2O3: New insight into sorption mechanisms by time-resolved laser fluorescence spectroscopy and extended X-ray absorption fine structure. Radiochim. Acta 2006, 94, 609.

(9) Moskaleva, L. V.; Nasluzov, V. A.; Rösch, N. Modeling adsorption of the uranyl dication on the hydroxylated (alpha-Al2O3(0001) surface in an aqueous medium. Density functional study. Langmuir 2006, 22, 2141.

(10) Perron, H.; Domain, C.; Roques, J.; Simoni, E.; Catalette, H. Theoretical first step towards an understanding of the uranyl ion sorption on the rutile TiO2(110) face: A DFT periodic and cluster study. Radiochimica Acta 2006, 94, 601.

(11) Flörsheimer, M.; Kruse, K.; Polly, R.; Abdelmonem, A.; Schimmelpfennig, B.; Klenze, R.; Fanghänel, T. Hydration of Mineral Surfaces Probed at the Molecular Level. Langmuir 2008, 24, 13434.

(12) Geckeis, H.; Rabung, T. Actinide geochemistry: From the molecular level to the real system. J. Contam. Hydrol. 2008, 102, 187.

(13) Kremleva, A.; Krüger, S.; Rösch, N. Density functional model studies of uranyl adsorption on (001) surfaces of kaolinite. Langmuir 2008, 24, 9515.

(14) Polly, R.; Schimmelpfennig, B.; Flörsheimer, M.; Kruse, K.; Abdelmonem, A.; 
Klenze, R.; Fanghänel, T. Theoretical investigation of the water/corundum (0001) interface. J. Chem. Phys. 2009, 130, 064702.

(15) Polly, R.; Schimmelpfennig, B.; Flörsheimer, M.; Rabung, T.; Klenze, R.; Geckeis, H. Quantum chemical study of inner-sphere complexes of trivalent lanthanide and actinide ions on the corundum (0001) surface. Radiochimica Acta 2010, 98, 627.

(16) Martorell, B.; Kremleva, A.; Krueger, S.; Roesch, N. Density Functional Model Study of Uranyl Adsorption on the Solvated (001) Surface of Kaolinite. J. Phys. Chem. C 2010, 114, 13287.

(17) Kremleva, A.; Krueger, S.; Roesch, N. Uranyl adsorption at (l $\left.\begin{array}{lll}0 & 1 & 0\end{array}\right)$ edge surfaces of kaolinite: A density functional study. Geochimica et Cosmochimica Acta 2011, $75,706$.

(18) Heberling, F.; Vinograd, V. L.; Polly, R.; Gale, J. D.; Heck, S.; Rothe, J.; Bosbach, D.; Geckeis, H.; Winkler, B. A thermodynamic entrapment model for the quantitative description of selenium(IV) coprecipitation with calcite. Geochimica et Cosmochimica Acta 2014, 134, 16.

(19) Jorg, G.; Buhnemann, R.; Hollas, S.; Kivel, N.; Kossert, K.; Winckel, S. V.; Gostomski, C. L. V. Preparation of radiochemically pure Se-79 and highly precise determination of its half-life. Applied Radiation and Isotopes 2010, 68, 2339.

(20) Ondraf/Niras, Technical Overview of the SAFIR 2 Report, Safety Assessment and Feasibility Interim Report 2; 2001.

(21) Aurelio, G.; Fernandez-Martinez, A.; Cuello, G. J.; Roman-Ross, G.; Alliot, I.; Charlet, L. Structural study of selenium (IV) substitutions in calcite. Chemical Geology 2010, 270, 249. 
(22) de Leeuw, N. H.; Parker, S. C. Atomistic simulation of the effect of molecular adsorption of water on the surface structure and energies of calcite surfaces. $J$. Chem. Soc., Faraday Trans. 1997, 93(3), 467.

(23) de Leeuw, N. H.; Parker, S. C. Surface structure and morphology of calcium carbonate polymorphs calcite, aragonite, and vaterite: An atomistic approach. J. Phys. Chem. B 1998, 102, 2914.

(24) Kerisit, S.; Parker, S. C.; Harding, J. H. Atomistic simulation of the dissociative adsorption of water on calcite surfaces. J. Phys. Chem. B 2003, 10\%, 7676.

(25) Kerisit, S.; Cooke, D. J.; Spagnoli, D.; Parker, S. C. Molecular dynamics simulations of the interactions between water and inorganic solids. J. Mater. Chem. 2005, $15,1454$.

(26) Perry, T. D.; Cygan, R. T.; Mitchell, R. Molecular models of a hydrated calcite mineral surface. Geochimica et Cosmochimica Acta 2007, 71, 5876.

(27) Bruno, M.; Massaro, F. R.; Prencipe, M. Theoretical structure and surface energy of the reconstructed 01.2 form of calcite $(\mathrm{CaCO}(3))$ crystal. Surf. Science 2008, $602,2774$.

(28) Stashans, A.; Chamba, G.; Pinto, H. Electronic structure, chemical bonding, and geometry of pure and Sr-doped CaCO3. J. Comp. Chem. 2008, 29, 343.

(29) Lardge, J. S. Investigation of the interaction of water with the calcite 1014 surface using ab-initio simulation. Ph.D. thesis, University College London, 2009.

(30) Lardge, J. S.; Duffy, D. M.; Gillan, M. J. Investigation of the Interaction of Water with the Calcite (10.4) Surface Using Ab Initio Simulation. J. Phys. Chem. C 2009, 113, 7207. 
(31) Lardge, J. S.; Duffy, D. M.; Gillan, M. J.; Watkins, M. Ab Initio Simulations of the Interaction between Water and Defects on the Calcite (10(1)over-bar 4) Surface. J. Phys. Chem. C 2010, 114, 2664.

(32) Bruno, M.; Massaro, F. R.; Prencipe, M.; Aquilano, D. Surface reconstructions and relaxation effects in a centre-symmetrical crystal: the 00.1 form of calcite (CaCO3). Cryst. Eng. Comm. 2010, 12, 3626.

(33) Raiteri, P.; Gale, J. D.; Quigley, D.; Rodger, P. M. Derivation of an Accurate Force-Field for Simulating the Growth of Calcium Carbonate from Aqueous Solution: A New Model for the Calcite-Water Interface. Journal of Physical Chemistry C 2010, 114, 5997.

(34) Demichelis, R.; Raiteri, P.; Gale, J. D.; Dovesi, R. A new structural model for disorder in vaterite from first-principles calculations. Chryst. Eng. Comm. 2012, $14,44$.

(35) Rigo, V. A.; Metin, C. O.; Nguyen, Q. P.; Miranda, C. R. Hydrocarbon Adsorption on Carbonate Mineral Surfaces: A First-Principles Study with van der Waals Interactions. J. Phys. Chem. C 2012, 116, 24538.

(36) Andersson, M. P.; Stipp, S. L. S. How acidic is water on calcite? J. Phys. Chem. C 2012, 116, 18779 .

(37) Demichelis, R.; Raiteri, P.; Gale, J. D.; Dovesi, R. Examining the Accuracy of Density Functional Theory for Predicting the Thermodynamics of Water Incorporation into Minerals: The Hydrates of Calcium Carbonate. J. Phys. Chem. C 2013, 117, 17814 .

(38) Demichelis, R.; Raiteri, P.; Gale, J. D.; Dovesi, R. Multiple structures of vaterite. Cryst. Growth Design 2013, 13, 2247. 
(39) Bruno, M.; Massaro, F. R.; Pastero, L.; Costa, E.; Rubbo, M.; Prencipe, M.; Aquilano, D. New Estimates of the Free Energy of Calcite/Water Interfaces for Evaluating the Equilibrium Shape and Nucleation Mechanisms. Cryst. Growth Des 2013, 13, 1170.

(40) Besson, R.; Favergon, L. Atomic-Scale Study of Calcite Nucleation in Calcium Oxide. J. Phys. Chem. C 2013, 117, 8813.

(41) de la Pierre, M.; Raiteri, P.; Gale, J. D. Structure and Dynamics of Water at Step Edges on the Calcite 1014 Surface. Chryst. Growth Des. 2016, 16, 5907.

(42) Hohenberg, P.; Kohn, W. Inhomogeneos electron gas. Phys. Rev. 1964, 136, B864.

(43) Kohn, W.; Sham, L. J. Self-consistent equations including exchange and correlation effects. Phys. Rev. 1965, 140, A1133.

(44) P. v. R. Schleyer and N. L. Allinger and T. Clark and J. Gasteiger and P. A. Kollman and H. F. Schaefer III and P. R. Schreiner,, Ed. The Encyclopedia of Computational Chemistry; Wiley: Chichester, 1998.

(45) Cheng, L.; Lyman, P. F.; Sturchio, N. C.; Bedzyk, M. J. X-ray standing wave investigations of the surface structure of selenite anions adsorbed on calcite. Surface Science 1997, 382, L690.

(46) Fenter, P.; Geissbühler, P.; DiMasi, E.; Srajer, G.; Sorensen, L. B.; Sturchio, N. C. Surface speciation of calcite observed in situ by high-resolution X-ray reflectivity. Geochim. Cosmochim. Acta 2000, 64, 1221.

(47) Geissbühler, P.; Fenter, P.; DiMasi, E.; Srajer, G.; Sorensen, L. B.; Sturchio, N. C. Three-dimensional structure of the calcite-water interface by surface X-ray scattering. Surface Science 2004, 573, 191. 
(48) Magdans, U.; Torrelles, X.; Angermund, K.; Gies, H.; Rius, J. Crystalline order of a water glycine film coadsorbed on the (104) calcite surface. Langmuir 2007, 23, 4999.

(49) Heberling, F.; Trainor, T. P.; anf P. Eng, J. L.; Denecke, M. A.; Bosbach, D. Structure and reactivity of the calcite-water interface. Journal of Colloid and Interface Science 2011, 354, 843.

(50) Fenter, P.; Sturchio, N. C. Calcite (104)-water interface structure, revisited. Geochimica et Cosmochimica Acta 2012, 97, 58.

(51) Fenter, P.; Kerisit, S.; Raiteri, P.; Gale, J. D. Is the Calcite-Water interface Understood? Direct comparison of Molecular Dynamics Simulations with Specular X-ray Reflectivity Data. J. Phys. Chem. C 2013, 11\%, 5028.

(52) Heberling, F.; Bosbach, D.; Eckhardt, J. D.; Fischer, U.; Glowacky, J.; Kramar, M. H. U.; Muller, S. L. H. S.; Neumann, T.; Pust, C.; Schafer, T.; Stelling, J.; Ukrainczyk, M.; Vinograd, V.; Vucak, M.; Winkler, B. Reactivity of the calcitewater-interface, from molecular scale processes to geochemical engineering. Applied Geochemistry 2014, 45, 158.

(53) Gao, Z.; Li, C.; Sun, W.; Hue, Y. Colloids and surface A: Physicochem. Eng. Aspects 2017, 520, 53.

(54) Kresse, G.; Hafner, J. Ab-initio molecular dynamics for open-shell transition-metals. Phys. Rev. B 1993, 48, 13115.

(55) Kresse, G.; Furthmüller, J. Efficient iterative schemes for ab initio total-energy calculations using a plane-wave basis set. Phys. Rev. B 1996, 54, 11169.

(56) Kresse, G.; Furthmüller, J. Efficiency of ab-initio total energy calculations for 
metals and semiconductors using a plane-wave basis set. J. Computer. Mater. Sci 1996, $6,15$.

(57) Perdew, J. P.; Burke, K.; Ernzerhof, M. Generalized gradient approximation made simple. Phys. Rev. Lett. 1996, r7, 3865.

(58) Blöchl, P. E. Projector augmented-wave method. Phys. Rev. B 1994, 50, 17953.

(59) Kresse, G.; Joubert, D. From ultrasoft pseudopotentials to the projector augmentedwave method. Phys. Rev. B 1999, 59, 1758.

(60) Kresse, G.; Furthmüller, K. VASP the Guide. Available from http://cms.mip.univie.ac.at/VASP".

(61) Janeček, J.; Netz, R. R.; Flörsheimer, M.; Schimmelpfennig, B.; Polly, R. Influence of Hydrogen Bonding on the Structure of the (001) Corundum-Water Interface. Density Functional Theory Calculations and Monte Carlo Simulations. Langmuir 2014, 30 (10), 2722 .

(62) Antao, S. M.; Hassan, I.; Mulder, W. H.; Lee, P. L.; Toby, B. H. In Situ Study of the R3c R3m Orientational Disorder on Calcite. Phys. Chem. Miner. 2009, 36, 159 .

(63) Antao, S. M.; Hassan, I. Temperature dependence of the structural Parameters in the Transformation of Aragonite to Calcite, as Determined from in situ Synchrotron X-ray Diffraction Data. Can. Mineral. 2010, 48, 1225.

(64) Wesołowski, T. A.; Parisle, O.; Ellinger, Y.; Weber, J. Comparative study of benzene center dot center dot center dot $\mathrm{X}(\mathrm{X}=\mathrm{O}-2, \mathrm{~N}-2, \mathrm{CO})$ complexes using density functional theory: The importance of an accurate exchange-correlation energy density at high reduced density gradients. J. Phys. Chem. 1997, 101, 7818. 
(65) Grimme, S. Semiempirical GGA-type density functional constructed with a longrange dispersion correction. J. Comp. Chem. 2006, 27, 1787.

(66) Grimme, S.; Antony, J.; Ehrlich, S.; Krieg, S. A consistent and accurate ab initio parametrization of density functional dispersion correction (dft-d) for the 94 elements H-Pu. J. Chem. Phys. 2010, 132, 154104.

(67) Klimež, J.; Bowler, D. R.; Michaelides, A. Phys. Review B 2011, 83, 195131.

(68) Arnaldsson, A.; Tang, W.; S. Chill, W. C.; Henkelman, G. Code: Bader Charge Analysis availiable at http://theory.cm.utexas.edu/henkelman/code/bader/.

(69) Wright, K.; Cygan, R. T.; Slater, B. Structure of the (10(1)over-bar4) surfaces of calcite, dolomite and magnesite under wet and dry conditions. Phys. Chem. Chem. Phys. 2001, 3, 839.

(70) Wickleder, M. S. Sodium selenite, Na2SeO3. Acta Crystallographica Section EStructure Reports Online 2002, 58, I103-I104.

(71) Ahlrichs, R.; Baer, M.; Häser, M.; Horna, H.; Kölmel, C. Electronic structure calculations on workstation computers: The program system turbomole. Chem. Phys. Lett. 1989, 162, 165.

(72) Eichkorn, K.; Treutler, O.; Oehm, H.; Haeser, M.; Ahlrichs, R. Auxiliary basis-sets to approximate Coulomb potentials. Chem. Phys. Lett. 1995, 242, 652.

(73) Treutler, O.; Ahlrichs, R. Efficient molecular numerical-integration schemes. J. chem. Phys. 1995, 102, 346.

(74) Arnim, M. V.; Ahlrichs, R. Performance of parallel TURBOMOLE for density functional calculations. J. Comp. Chem. 1998, 19, 1746.

(75) Eichkorn, K.; Treutler, O.; Oehm, H.; Haeser, M.; Ahlrichs, R. Auxiliary basis-sets to approximate Coulomb potentials. Chem. Phys. Lett. 1995, 240, 283. 
(76) Eichkorn, K.; Weigend, F.; Treutler, O.; Ahlrichs, R. Auxiliary basis sets for main row atoms and transition metals and their use to approximate Coulomb potentials. Theo. Chem. Acc. 1997, 97, 119.

(77) Sierka, M.; Hogekamp, A.; Ahlrichs, R. Fast evaluation of the Coulomb potential for electron densities using multipole accelerated resolution of identity approximation. J. Chem. Phys. 2003, 118, 9136.

(78) Heberling, F.; Paulig, L.; Nie, Z.; Schild, D.; Finck, N. Morphology Controls on Calcite Recrystallization. Environ. Sci. Technol. 2016, 50 (21), 11735. 


\section{Tables}

1

2

4

5

6

7

8

9

10

11

12

13

14

15

16

17

18

19

20

21

22

23

24

25

26

27

28

29

30

31

32

33

34

35

36

37

38

39

40

41

42

43

44

45

46

47

48

49

50

51

52

53

54

55

56

57

58

59

60 
Table 1: Results for the monoclinic and hexagonal unit cells of calcite ( $a, b, c$, internuclear distances $\mathrm{r}_{i}$ and interlayer distances $\mathrm{d}_{i}$ in $\mathrm{pm}, \beta, \theta$ in ${ }^{\circ}$, Temperature in Kelvin).

\begin{tabular}{|c|c|c|c|c|c|c|c|c|}
\hline & \multicolumn{4}{|c|}{ "Monoclinic } & \multicolumn{4}{|c|}{ 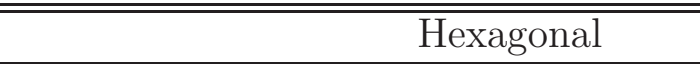 } \\
\hline & \multicolumn{3}{|c|}{$\begin{array}{l}\text { theoretical } \\
\text { this work }\end{array}$} & \multirow[t]{2}{*}{$\begin{array}{c}\text { experimental } \\
49\end{array}$} & \multicolumn{3}{|c|}{$\begin{array}{l}\text { theoretical } \\
\text { this work }\end{array}$} & \multirow[t]{2}{*}{37} \\
\hline & DFT & $\mathrm{DFT}-\mathrm{D} 2^{65}$ & DFT-D3 $3^{66}$ & & $\mathrm{DFT}$ & DFT-D2 ${ }^{65}$ & DFT-D3 ${ }^{66}$ & \\
\hline \multicolumn{9}{|c|}{ "unit cell } \\
\hline $\bar{a}$ & 818 & 818 & 819 & 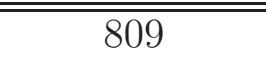 & 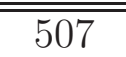 & 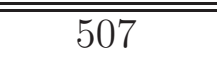 & 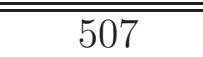 & $\bar{~} 505$ \\
\hline$b$ & 506 & 506 & 506 & 499 & 507 & 507 & 507 & 505 \\
\hline$c$ & 643 & 643 & 644 & 637 & 1779 & 1770 & 1779 & 1731 \\
\hline$\beta$ & 107.3 & 107.3 & 107.6 & 107.8 & 120.0 & 120.0 & 120.0 & 120.0 \\
\hline \multicolumn{9}{|c|}{ Internuclear distances $\mathrm{r}_{i}$} \\
\hline $\mathrm{r}_{C a-C a}$ & 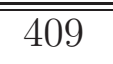 & 409 & "409 & 405 & 408 & 408 & 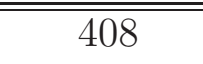 & - \\
\hline & 505 & 505 & 505 & & 507 & 507 & 507 & - \\
\hline $\mathrm{r}_{C a-C}$ & 325 & 325 & 325 & 321 & 325 & 325 & 325 & - \\
\hline $\mathrm{r}_{C a-O}$ & 239 & 239 & 239 & 236 & 238 & 238 & 238 & 239 \\
\hline $\mathrm{r}_{C-O}$ & 130 & 130 & 130 & 129 & 130 & 130 & 130 & 130 \\
\hline \multicolumn{9}{|c|}{$(10 \overline{1} 4)$ interlayer distances $\mathrm{d}_{i}$} \\
\hline $\mathrm{d}_{(10 \overline{1} 4), C a-C a}$ & 306 & 304 & 307 & 304 & 303 & 306 & 306 & $\overline{-1}$ \\
\hline \multicolumn{9}{|c|}{ te tilt angle of the $\mathrm{CO}_{3}$ groups } \\
\hline$\theta_{\mathrm{CO}_{3}}$ & 44.6 & 44.3 & 44.4 & 44.7 & 44.2 & 44.2 & 44.2 & \\
\hline
\end{tabular}

Table 2: Charges of the ions

\begin{tabular}{l|ccc|c}
\hline \hline & \multicolumn{3}{|c}{ dry surface } & bulk \\
& surface layer & second layer & third layer & \\
\hline \hline $\mathrm{Ca}$ & +1.604 & +1.644 & +1.656 & +1.652 \\
$\mathrm{O}$ & -1.106 & -1.117 & -1.119 & -1.136 \\
$\mathrm{C}$ & +1.694 & +1.716 & +1.724 & +1.757 \\
\hline \hline
\end{tabular}




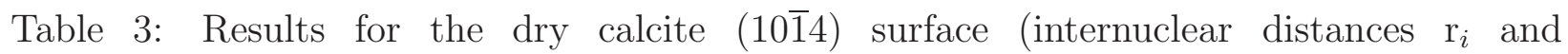
interlayer distances $\mathrm{d}_{i}$ in $\mathrm{pm}, \theta$ in ${ }^{\circ}$ ).

\begin{tabular}{l|c|c|l}
\hline \hline & without restrictions & $\begin{array}{c}\text { with } \\
\text { restrictions }\end{array}$ & \\
\hline \hline $\mathrm{d}_{(10 \overline{1} 4), C a-C a}$ & 298 & 298 & \\
\hline $\mathrm{r}_{C a-C a}$ & 409 & 409 & $\begin{array}{c}\text { within surface layer } \\
\text { between surface and } \\
\end{array}$ \\
& $401-402$ & $401-402$ & first subsurface layer \\
\hline $\mathrm{r}_{C a-C}$ & $323,325,329$ & $322,325-326,329$ & \\
$\mathrm{r}_{C a-O}$ & $231,238-240$ & $231,238-240$ & \\
$\mathrm{r}_{C-O}$ & $128-132$ & $128-132$ & \\
\hline$\theta_{C O_{3}}$ & 41.2 & 42.1 & \\
\hline \hline
\end{tabular}

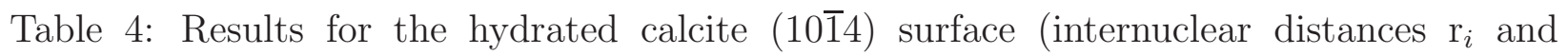
interlayer distances $\mathrm{d}_{i}$ in $\mathrm{pm}$ ).

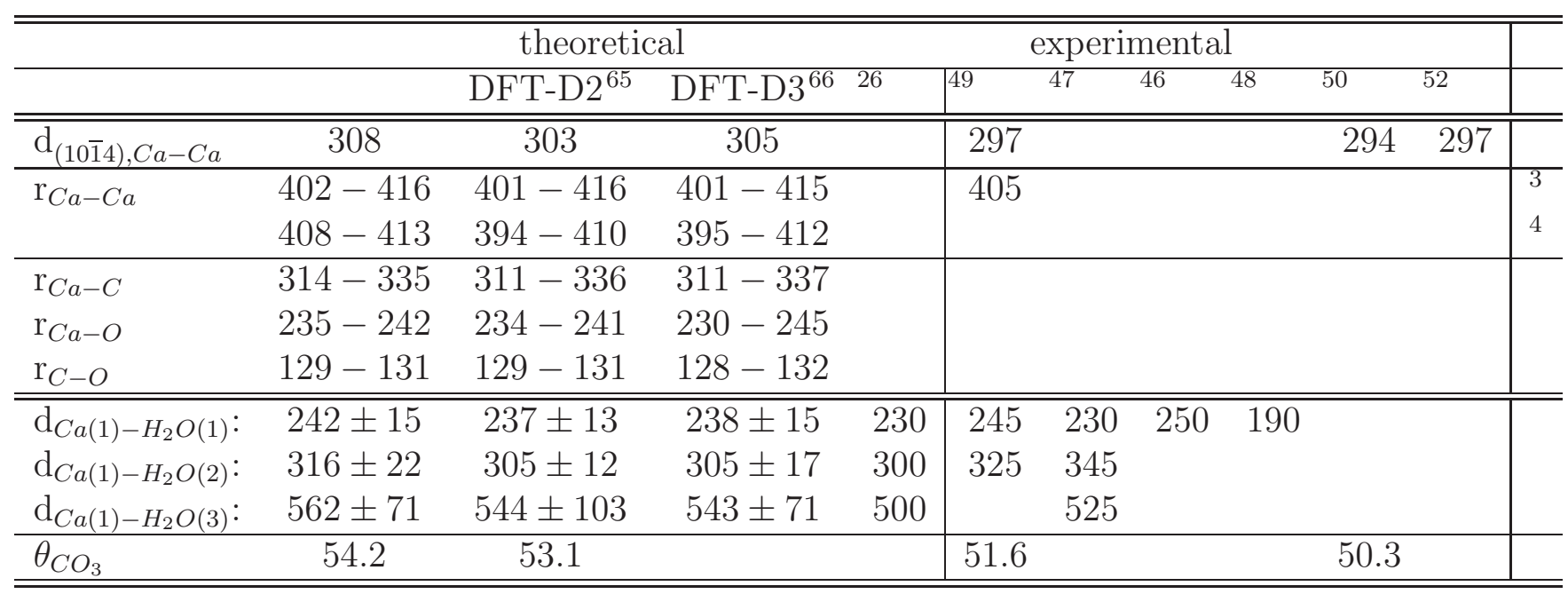


Table 5: Local changes in the crystal structure of calcite upon incorporation of $\mathrm{SeO}_{3}^{2-}$ into the monoclinic and hexagonal unit cell. These distances are only in the vicinity of the substitution. $1^{\text {st }}, 2^{\text {nd }}$ : first and second shell of $\mathrm{Ca}^{2+}$ ions around the $\mathrm{SeO}_{3}^{2-}$ (internuclear distances $\mathrm{r}_{i}$ in $\mathrm{pm}$ ).

\begin{tabular}{lcc}
\hline \hline & monoclinic & hexagonal \\
\hline \hline $\mathrm{r}_{C a-C a}$ & $416-423$ & $414-424\left(1^{s t}\right)$ \\
& $398-415$ & $398-410\left(2^{\text {nd }}\right)$ \\
& $496-510,544-545$ & $499-500,549\left(1^{\text {st }}\right)$ \\
& $467-488,503-511$ & $466,505-516\left(2^{\text {nd }}\right)$ \\
$\mathrm{r}_{C a-S e}$ & 324 & 326 \\
& $356-358$ & $356-357$ \\
$\mathrm{r}_{C a-C}$ & $308-335$ & $306-337$ \\
$\mathrm{r}_{C a-O}$ & $233-246$ & $234-246$ \\
$\mathrm{r}_{C-O}$ & $130-131$ & 130 \\
$\mathrm{r}_{S e-O}$ & 173 & 173 \\
\hline \hline
\end{tabular}

Table 6: Local changes in the crystal structur upon incorporation of $\mathrm{SeO}_{3}^{2-}$ into calcite

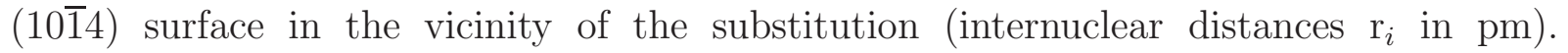

\begin{tabular}{lccc}
\hline \hline & dry surface & hydrated surface & comment \\
\hline \hline $\mathrm{r}_{\mathrm{Ca}-\mathrm{Ca}}$ & $395-403$ & $395-411$ & between surface and second layer \\
& $419-427$ & 426 & within surface plane \\
& 499,544 & $488-519$ & between surface and second layer \\
& $480-510$ & $494-538$ & within surface plane \\
$\mathrm{r}_{\mathrm{Ca}-\mathrm{Se}}$ & 385 & 379 & between surface and second layer \\
\multicolumn{5}{c}{} & $336,344,353,366$ & $335,346,354,354$ & within surface plane \\
$\mathrm{r}_{\mathrm{Ca}-\mathrm{C}}$ & $308-337$ & $312-342$ & \\
$\mathrm{r}_{\mathrm{Ca}-\mathrm{O}}$ & $229-246$ & $230-249$ & \\
$\mathrm{r}_{\mathrm{C}-\mathrm{O}}$ & $128-132$ & $128-132$ & \\
$\mathrm{r}_{\mathrm{Se}-\mathrm{O}}$ & $170,175,175$ (surface) & $172,173,174$ & \\
$\mathrm{r}_{\mathrm{Se}-\mathrm{O}}$ & 173 (second and third ayer) \\
\hline \hline
\end{tabular}




\section{$9 \quad$ Figures}

(a)

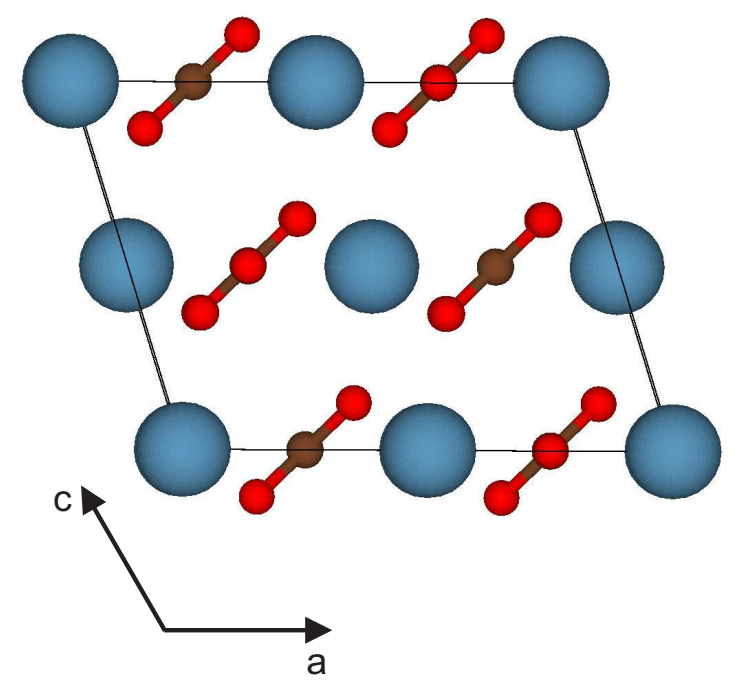

(b)

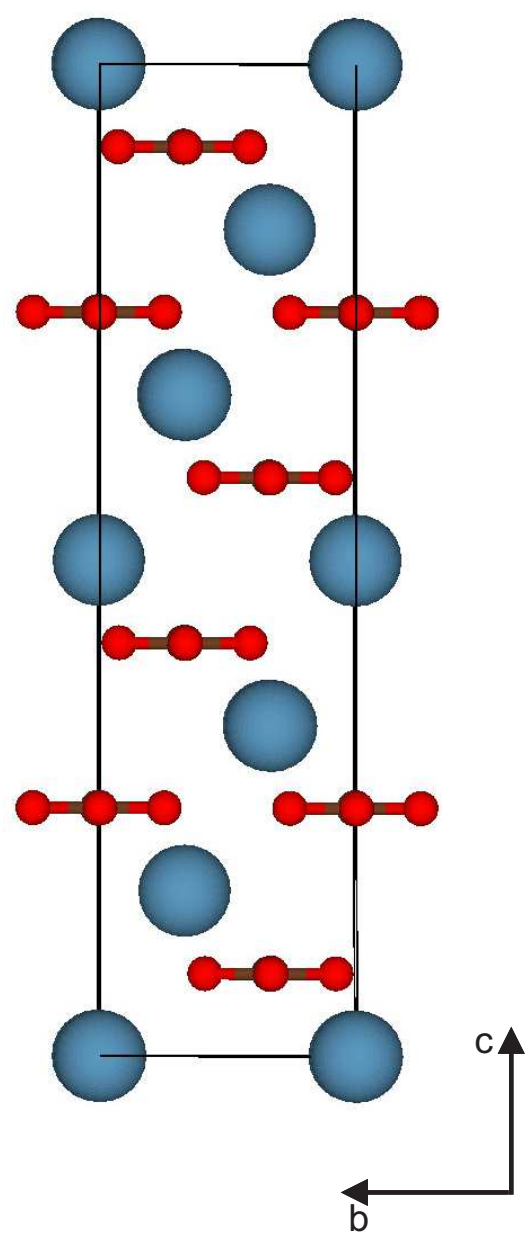

Figure 1: (Color online) The monoclinic (a) and hexagonal (b) unit cell of calcite (Ca: blue, O: red, C: brown) 

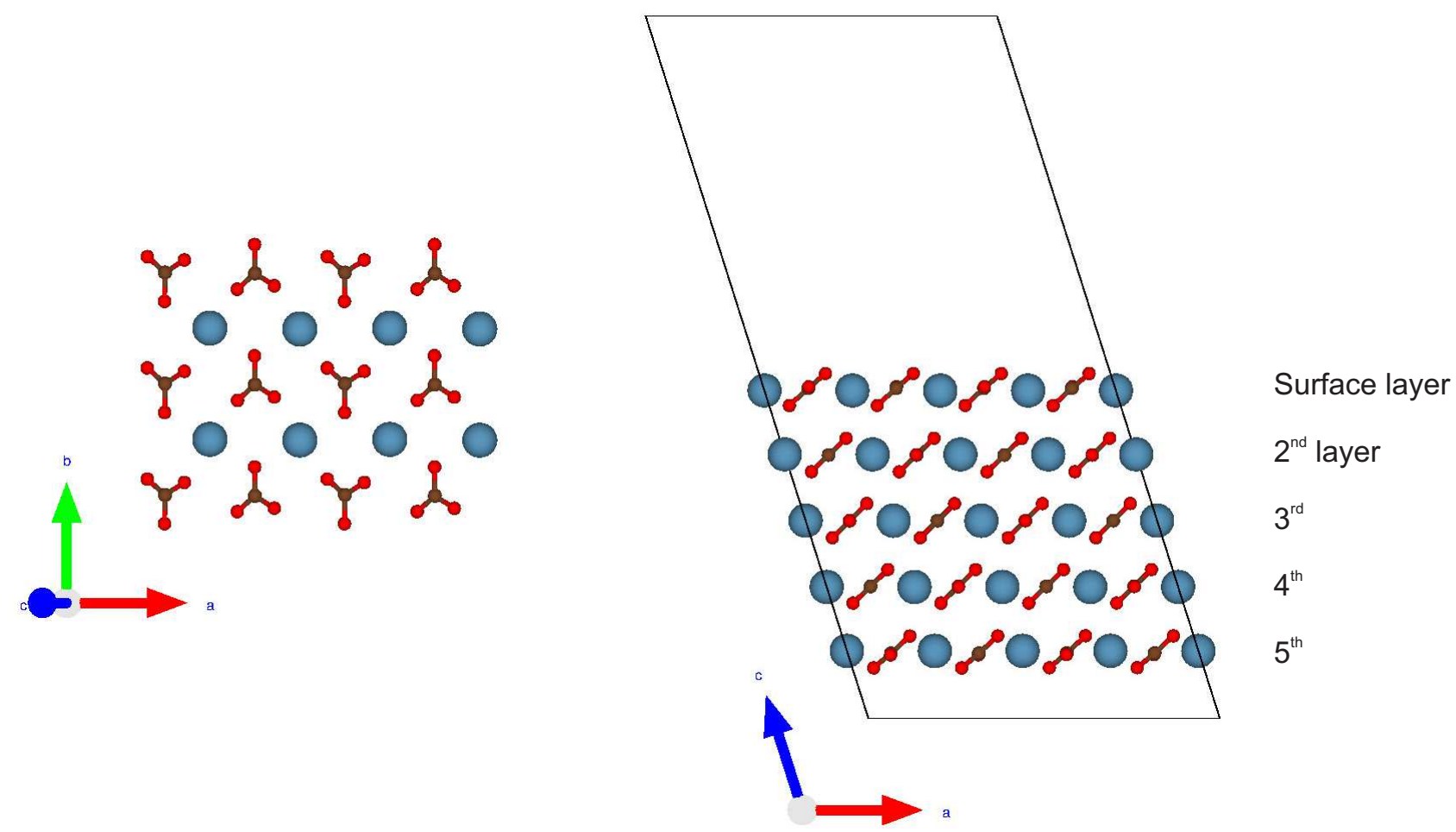

top view

side view

Figure 2: (Color online) Top view of the first surface layer and side view of the

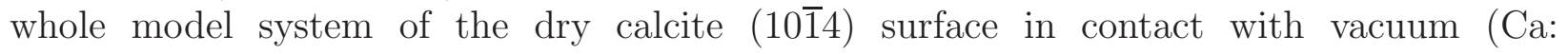
blue, O: red, C: brown) 
1

2

3

4

5

6

7

8

10

11

12

13

14

15

16

17

18

19

20

21

22

23

24

25

26

27

28

29

30

31

32

33

34

35

36

37

38

39

40

41

42

43

44

45

46

47

48

49

50

51

52

53

54

55

56

57

58

59

60

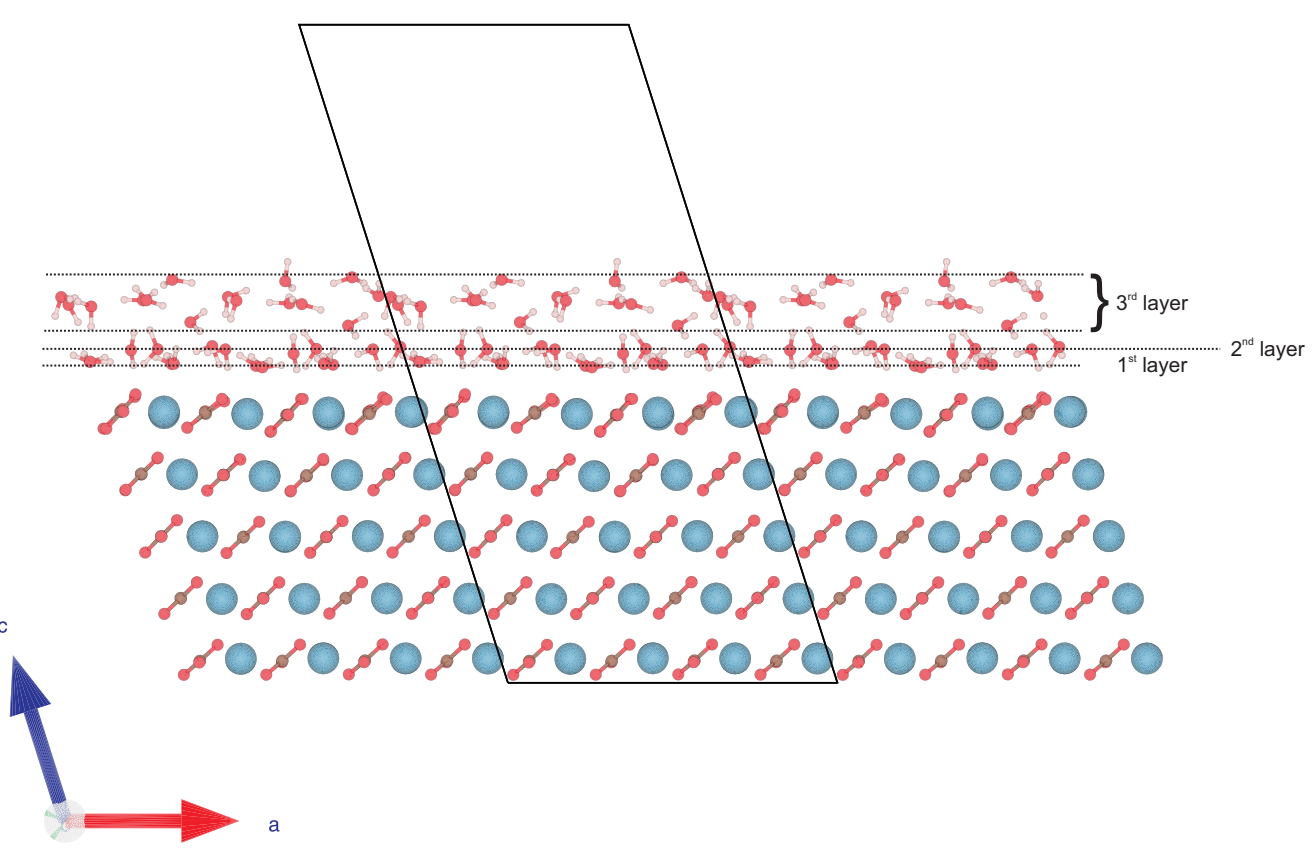

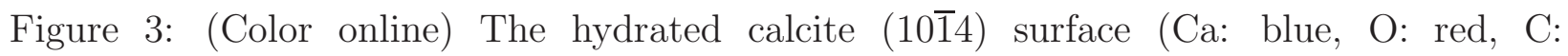
brown, H: white) 


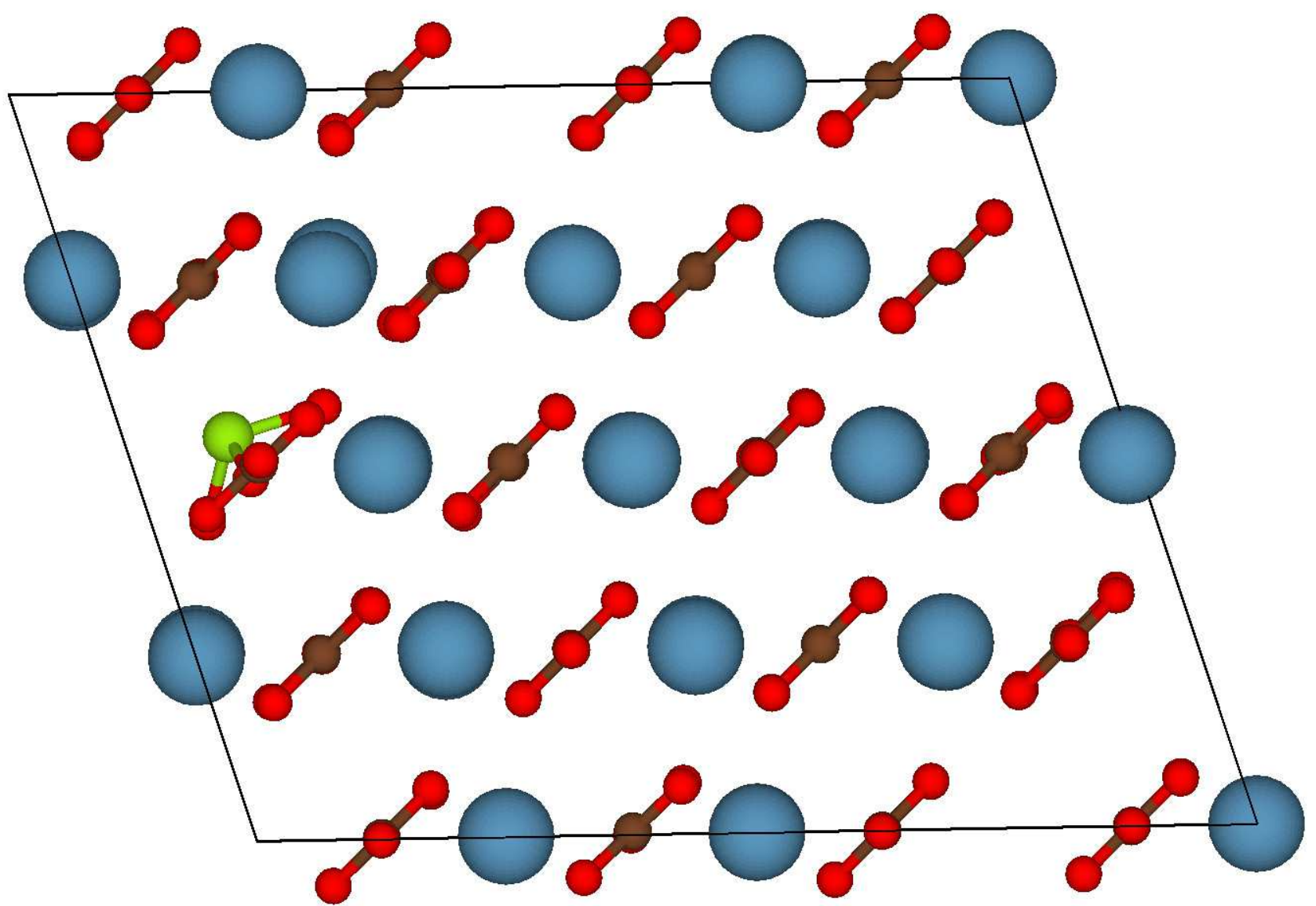

Figure 4: (Color online) Incorporation of selenite $\mathrm{SeO}_{3}^{2-}$ into a monoclinic $2 \times 2 \times 2$ super cell of calcite (Ca: blue, O: red, C: brown, Se: green) 
Figure 5: (Color online) Incorporation of selenite $\mathrm{SeO}_{3}^{2-}$ into a hexagonal $2 \times 2$ super cell of calcite (Ca: blue, O: red, C: brown, Se: green)

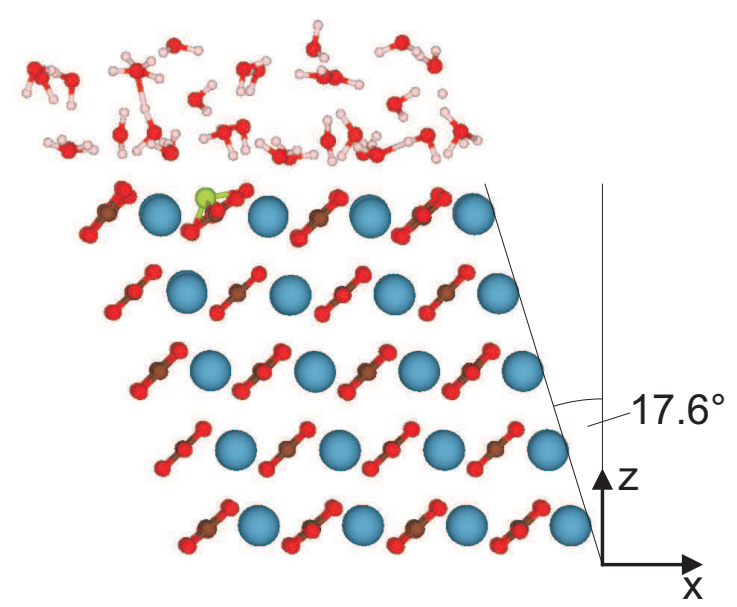

Figure 6: (Color online) Incorporation of selenite into the hydrated calcite (10̄14) surface (Ca: blue, O: red, C: brown, H: white, Se: green) 


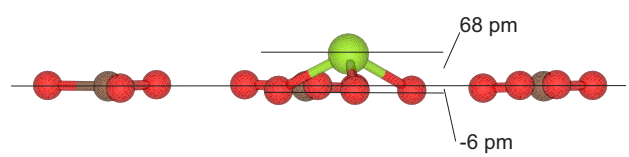

Figure 7: (Color online) Relative position of $\mathrm{SeO}_{3}^{2-}$ in the bulk phase for the hexagonal unit cell (Ca: blue, O: red, C: brown, Se: green)

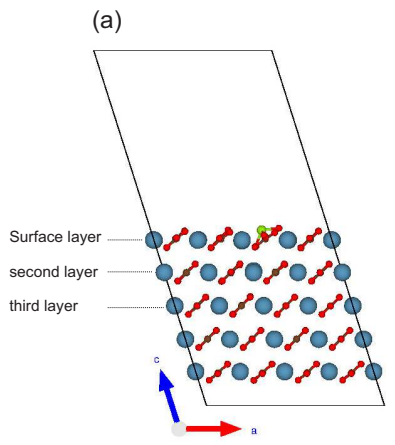

(b)

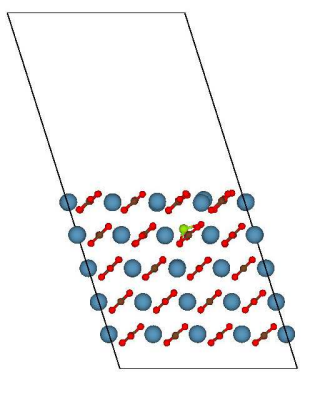

(c)

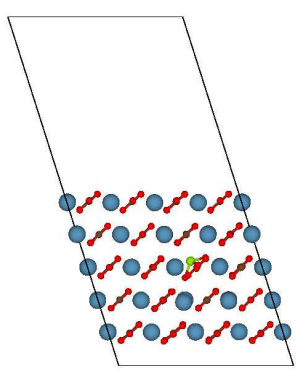

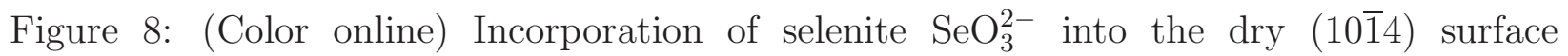
and subsurface layers of calcite. (a), (b) and (c) show the incorporation into the surface, the second and the third layer, respectively (Ca: blue, O: red, C: brown, Se: green)

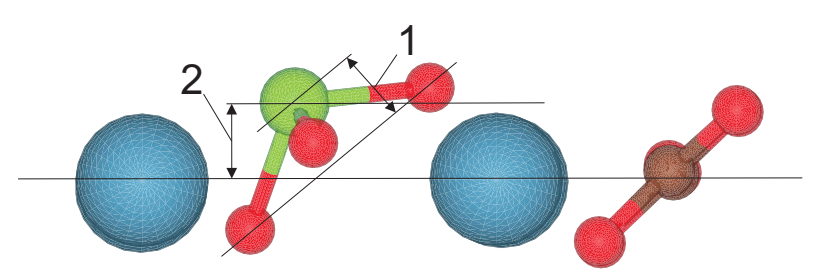

Figure 9: (Color online) Relative position of $\mathrm{SeO}_{3}^{2-}$ for the surface incorporation (Ca: blue, O: red, C: brown, Se: green) 


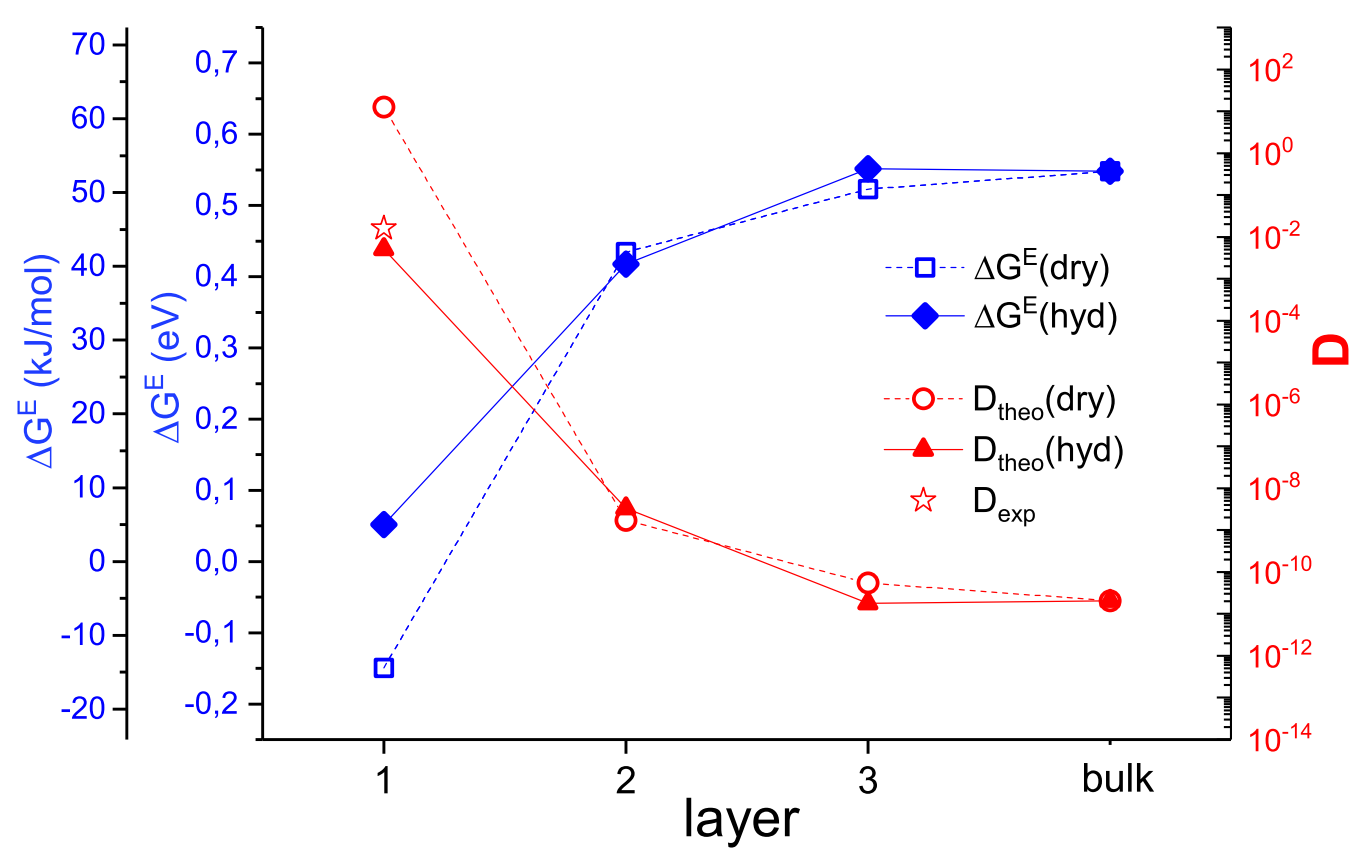

Figure 10: (Color online) Relative incorporation energies $\Delta G_{\text {incorp }}$ (as defined in eq. (2) and (3) and thermodynamic partition coefficient $\mathbf{D}$ of selenite $\mathrm{SeO}_{3}^{2-}$ into the dry

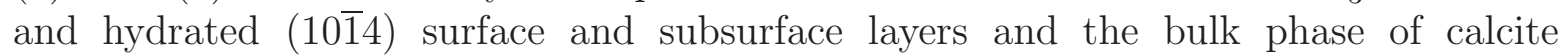



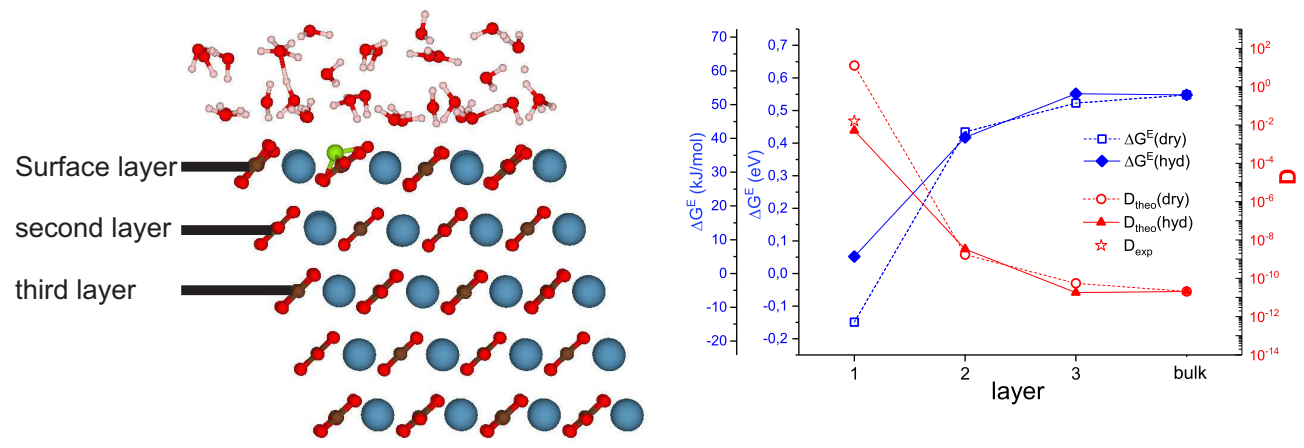

Figure 11: (Color online) TOC graphics 